\title{
Is Multilingualism as a Deficit or Opportunity? Teachers and Students Attitude in the Selected Primary School of Bale and West Arsi Zone
}

\author{
Befkadu Mebratu Jamaica Kebede Elias Admasu
}

\begin{abstract}
The focus of this study was to examine students and teachers attitude towards multilingualism in the selected primary school of Bale and west Arsi zone. The study employed mixed research method. On the basis of this eight primary schools from Goba, Robe, Shashemene and Ginir town were selected as a sample schools. Purposive sampling technique was employed to select schools, students' grade level, teachers and community members, whereas random sampling was chosen to select students. In total of 377 (Grade 7 and 8) students and 48 language teachers filled the questionnaire survey and 8 focus group discussions was conducted among teachers. In order to get detailed information the researchers employed an individual interview with 16 community members. Mixed data analysis method is selected in reporting and analyzing the result. The data collected through interview and focus group discussion qualitatively analyzed. However, questionnaires are analyzed qualitatively and quantitatively ( average mean and standard deviation, independent t-test and partial correlations) because the questioners organized both open and close-ended question types.
\end{abstract}

DOI: $10.7176 / \mathrm{JCSD} / 62-03$

Publication date:October $31^{\text {st }} 2020$

\section{Background of the Study}

Before 1970's most peoples (particularly, people in Europe and North America who speak a 'big' language) to be bilingual or multilingual is considered as aberration and a deficit for social, economic and political development. Jonathan pool's article on "national development and linguistic diversity" summarizes this idea.

Language diversity of one sort or another is held to cause the retardation of development, both political and economic. Language diversity, it is claimed, aggravates political sectionalism; hinders inter-group cooperation, national unity, and regional multinational cooperation; impedes political enculturation, political support for the authorities and the regime, and political participation; and holds down governmental effectiveness and political stability. Similarly it is said that language diversity slows economic development, by, for example, breaking occupational mobility, reducing the number of people available for mobilization into the modern sector of the economy, decreasing efficiency, and preventing the diffusion of innovative techniques (Pool, 1969; 1).

Moreover, Edwards (1994) explained that even if above 5,000 languages are spoken in our world only a quarter of all states (less than 40 countries) recognize more than one language. Also, even in those countries in which two or more varieties have legal status, one language is usually predominant, or has regional limitations, or carries with it disproportionate amounts of social, economic and political power.

Government's unfair treatment of language creates a negative attitude towards the language with in the societies. Different scholars define language attitude differently based on attitude towards the language itself and attitude towards the language and the speakers of the language perspectives. For example, Crystal (1992) cited in Sirgar (2010:12) defines language attitude from the attitude of language itself as "the feelings people have about their own or other different languages". Others also define language attitude from another perspective. They define it not only the attitudes of the language itself but also from the speakers of the language perspective. For instance, Baker (1992) cited in Mckenzie (2010:25) defines it as "language attitude is an umbrella, which includes attitude towards learning the new languages, community \& minorities, attitudes of parents towards language lessons, language groups, and use of specific languages." The above points show that, this definition of language attitude incorporates not only attitude towards language itself but also attitude towards language groups, communities and speakers of the languages.

The Federal Democratic Republic of Ethiopia (FDRE) government's Education and Training Policy (1994) stated the following core points regarding language use:

1. Bearing in mind the pedagogical advantage of the child and the rights of ethnic groups to develop their languages, primary education will be given in the ethnic languages

2. Ethnolinguistic groups can select either their own ethnic language or a language of wider communication as a medium of instruction.

3. The language of teacher training for kindergarten and primary education will be the nationality language used in the area.

4. Amharic will be given as a subject on the basis of its historical status as a language of wider 
communication across the country.

5. English will be the medium of instruction for secondary and higher education.

6. Students can choose and learn at least one nationality language and one foreign language.

7. English will be taught as a subject starting from grade one.

8. The necessary steps will be taken to strengthen language teaching at all levels. (Educational and Training policy, April1994;23-24)

The FDRE constitution as well as Education \& training policy give recognition for the local language to be thought as an academic and instructional language with the aim of creating citizen who are competent in local, national and international languages. But in the implementation process there are several problems to be taken seriously. From the researchers observation there is what Colin Baker defines as a "language conflict attitude": "the underlying assumption is of competition, one language threatening the other. Positive consequences for one language imply negative consequences for the other language. This gives the impression of languages existing in a kind of balance. As one prospers the other declines" (1992: 77).

In addition some parents are disappointed that their children are learning their own languages at school. It is common to hear such comments/questions as: 'why you choose the department (indigenous languages) you already speak?'

Several studies were conducted concerning attitude towards multilingualism. For instance, Lefebvre (2012) found that students' fear of failure and peer-to-peer shaming when learning a new language can leave them feeling ambivalent toward French. This is not to say that the student experience is overwhelmingly negative; however, student attitudes seem to fall somewhere between their learned value for multilingualism and their lived experiences.

Guerini (2007) study on Multilingualism and language attitudes in Ghana indicates that using an indigenous language (Akan) as medium of instruction in the local educational system would be opposed by both native and non-native speaker of language. They perceive the language as unfit for use in formal, technical and specialized domains, and value a command of the English language as one of the most important skills that formal education is expected to provide.

As far as our knowledge concerned there is no formal study conducted on attitude towards multilingualism in Ethiopia as general and in Bale zone specifically except Eshetu (2006E.C). But Eshetu's study makes only comparison among the three region students' attitude, motivation and interest towards Amharic who took as their second academic language. His study doesn't mention why they develop negative attitude towards the language and not investigate teachers' impact on students' motivation to develop their language competence.

\section{Statement of the Problem}

Language is a source and means of articulation of educational concepts, beliefs, prejudices, values, tradition, history and past achievement experiences (Cummins, 1999). It indicates that, through language everybody can express what he/she wants to say for others. Wolff (2006) in Heugh, et al (2007:8) strengthen the above idea that, "language is not everything in education, but without language everything is nothing in education". Therefore, language plays a crucial role in education.

Ethiopia is a country, which includes multilingual and multicultural societies. In addition to foreign languages like English, French, Arabic, Italian, there are more than 80 languages actively spoken in Ethiopia (Cohen, 2000 \& Daniel Alemu and Abebayehu Tekleselassie, 2011). So, Multilingualism is basic feature of our society.

Crystal (2011) Contemporary patterns of global communication and immigration have made multilingual education programmes a way of allowing children to experience their rich multilingual backgrounds as an advantage and as a means of thriving in a multilingual world. Giving children proficiency in the language spoken in their homes (L1) as well as the language spoken by the larger community (L2, L3, L4, etc.) can benefit individuals and society by increasing cognitive skills, humanistic understanding, achievement, economic benefits, linguistic ability, social skills and political cooperation between groups. Regarding this Zelalem (2012) suggests that speakers of major language, especially Amharic, should realize the advantages and start to learn language of their interest. Afan Oromo and Tigrigna would be better candidates in this regard for knowledge of three languages may enable speakers to communicate with at least seventy five percent of the whole population.

Meyer (2006) cited in Zelalem (2012) has pointed out that Amharic is spoken by $80 \%$ of the population in Ethiopia both as first and second language. The role of Amharic is therefore still preponderant in national and public functions. On the other hand, Zelalem (2012) recommend that the Ethiopian Language policy must take in to serious consideration the emerging "black skin white mask"1 children who hate using indigenous languages and even want to be "native speakers of English" especially in towns and cities.

Moreover, Eshetu (2006 E.C) study on Multiethnic Ethiopian students attitude, motivation and interest to Amharic and their academic achievement as a second language in three regions - Tigray, Afar and Oromia. His

\footnotetext{
${ }^{1}$ It is Fanon term mentioned in Kembo Sure \& Ogachi (2009) and Zelalem (2012)
} 
finding indicates that students of Oromia have less positive attitude, motivation and interest to learn Amharic, as a result their academic achievement is relatively low.

In addition, our summer in service students (Amharic Language and Literature) conducted a study for their BA degree partial fulfilment. Especially, the studies conducted on Bale zone indicates most students were not interested to learn Amharic. Even some students leave the class when Amharic teacher come in and/or prepare several false reasons not to attend the class. In line with this, there were large numbers of children (Specifically in Goba, Robe, Ginir and Shashemene) who are not proficient in Afan Oromo (Even if they were born in this bilingual context). Based on these the researchers motivated to conduct a study entitled on "Teacher and students attitude towards multilingualism in some selected full cycle primary school of Bale and West Arsi zone". Our study intended to answer the following research question.

1. What are the attitudes of the students to second/foreign languages at school?

2. What are the attitudes of the teachers towards the aspects of multilingualism in school?

3. How the communities support students to learn their and others language?

4. What are the major obstacles that face students in their $2^{\text {nd }}$ and $3^{\text {rd }}$ language learning?

5. What are the possible solutions to resolve the challenges which face students in language learning?

\section{Objectives of the Study}

The general objective of the study was to examine student and teachers' attitudes towards multilingualism in some selected primary school of Bale and West Arsi zone. Besides to these, the study will have the following specific objectives

$\checkmark \quad$ To investigate how young learners feel about languages and the use of different languages around them.

$\checkmark$ To assess whether the attitudes and personal beliefs of teachers regarding multilingualism affect the methods used in classrooms on a daily basis.

$\checkmark \quad$ To describe parents support towards their students language learning.

$\checkmark \quad$ To identify the major challenges in students $2^{\text {nd }}$ and $3^{\text {rd }}$ language learning.

$\checkmark$ To forward possible solution for the challenges that hinder students in their language learning.

\section{Significance of the Study}

In the bilingual or multilingual community, language choice for every day communication is personal, but for instructional purpose the language choice can be made collectively by the community and/or by the government. Even if educational language decision was made on the basis of attitudinal survey, unfavorable attitude cannot be completely avoided because the interest of all people could not be the same. So, research findings on the area of students' attitude towards multilingualism and its effect on academic performances is scarcely existent in Ethiopian context. This study will attempt to contribute some theoretical and practical basis for such relationship. It is also expected that the result point out some of the reasons for the unfavorable attitude of students toward using diverse language in the school. Thirdly, the findings is expected in helping the people to be aware of the factors that affect the attitude towards their and others' language and hence work towards the development of better understanding. Fourthly, the result of the study create awareness for parents to participate actively in their children language learning process especially in multilingual education practices. Finally, the study gives an insight to other researchers who are interested in studying further about attitudes of multilingualism.

\section{Scope of the Study}

The study covers eight primary schools of Goba, Robe, Shashemene and Ginir towns. The reason to select these schools was the presence of bilingual school (schools which teach students in more than two languages). The selected schools' Afan Oromo, Amharic and English subject teachers were included in the study purposively due to their great contribution for students' language development. But this doesn't mean other subject teachers have no role in students' language improvement. Thus, the view of other subject teachers not incorporated in the study. Concerning participation of students' Grade 7 and 8 students are involved by assuming that they can give better responses in the questionnaire due to their 7 and 8 years stay in the schools. In addition, community members were taken as a source of information based on their active participation.

\section{Operational Definition of Terms}

Monolinguals - individuals who use one language and may be proficient at using a number of different varieties of the language together with different registers in the variety

Bilinguals- are often described as persons who use two languages, and bilingualism- is 'the ability to speak two languages' or 'the habitual use of two languages colloquially'

Multilingual - is a person who has "the ability to use three or more languages, either separately or in various degrees of code-mixing (Edwards, 1994)

National language- is the language which has some connection — de facto or de jure — with a people and perhaps, 
by extension, the territory they occupy (Ball, 2010, p. 7, 59).

Majority language - is simply the language that the majority of the population of a particular place speaks.

Home language - is a term widely used to describe a language spoken in the home; often used when one's home language is different from the main language spoken in society.

Native language - refers to the language that a person has spoken from earliest childhood; also referred to as the learner's 'mother tongue' or 'home language' (Ball, 2010, p. 8, 60).

\section{Second Language}

Foreign language

Theoretical Frameworks of Language Attitude

Mentalist and behaviorist are the two approaches for investigating language attitude. With regard to mentalist view, "attitude is an internal state of readiness, and it cannot be observed directly but inferred from self-reporting data" (McKenzie, 2010: 21, Fasold, 1984:147). According to this view attitude is a covert behavior and it is necessary to use self-reporting mechanisms of collecting data. Social psychologists who accepted behaviorist view consider an attitude as a single unit, while according to mentalist view, it has three sub-components such as knowledge (cognitive element), feeling (affective element) and action (behavioral element) (Fasold, 1984: 148 \& McKenzie, 2010: 21). Since the researchers depend on the individuals' self-report what their attitudes are, it is often questionable validity and infers from behavior take the researcher one-step away from what he actually observed (Fasold, 1984:147).

In contrast to this, according to Mckenize (2010:2), behaviorist consider attitude as "a dependent variable and it can be determined by observing actual behavior in social situation." So that, attitude considered as overt behavior for behaviorist. As Fasold (1984: 147) states, the study of attitudes in the behaviorist view makes research easier to undertake because it does not need self-reporting and indirect inference. The only necessary tasks are observe, tabulate, and analyze overt behavior. However, Baker (1992:16) cited in McKenzie (2010: 21) argues that observation of external behavior can easily result in mis-categorization or wrongful explanation and as such, cannot be viewed as a reliable predictor.

However, the researcher uses mentalist view to investigate attitudes of teachers, parents and students towards using more than two languages as academic and instructional in the school. It is because mentalist view facilitates the understanding of this topic through providing emphasis to the respondents feeling, knowledge and action for investigating their attitude. Moreover, since "internal mental states cannot be directly observed" (Ihemere, 2006; 195), mentalist view enables the researcher to gather data through self-reporting mechanism of data collecting tools.

\section{The Concept of Bi/Multilingualism}

In the popular view, being bi/multilingual equals being able to speak two or more languages perfectly; this is also the approach of Bloomfield (1935: 56) cited in Clyn (1997), who defines bi/multilingualism as 'the native-like control of two/three languages'. In contradistinction to this definition which includes only 'perfect bi/multilinguals'. Macnamara (1967a) cited in Clyn (1997) proposes that a bi/multilingual is anyone who possesses a minimal competence in only one of the four language skills, listening comprehension, speaking, reading and writing, in a language other than his mother tongue. Between these two extremes one encounters a whole array of definitions as, for example, the one proposed by Titone (1972) cited in Clyn (1997), for whom bi/multilingualism is the individual's capacity to speak a second/third language while following the concepts and structures of that language rather than paraphrasing his or her mother tongue

Although linguists debate the issue of whether or not an individual can have more than one native language, for the purposes of this study, it will be assumed that a person can be a native speaker of one or more languages. However, linguists and educators often refer to varying kinds of bi/multilingualism; Erika Hoff expands on these varying kinds in her book, Language Development. Simultaneous bilingualism is when children acquire two languages at the same time. This is often the case for children who are born to parents who are native speakers of two different languages, or for children who are born into bilingual cultures (Hoff, 2001:368).

In contrast, sequential bilingualism is when children acquire a second language after the first has begun to develop (Hoff, 2001: 368). This type of language acquisition can result in a sort of sub-coordinate bilingualism, in which a first language is used to think through and define words in the second language (Romaine, 1989: 77). Finally, biliteracy specifically refers to the acquisition and learning of decoding and encoding print skills in two distinct languages.

\section{Advantages of Multilingualism and Multilingual Education}

Diversity is directly related to stability; variety is important for long term survival. Our success on this planet has been due to [...] ability to different kinds of environment over thousands of years (atmospheric as well as culture). Such ability is born out of diversity. Thus language and cultural 
diversity maximizes chances of human success and adaptability. (Colin Baker, 2001; 281 cited in

Tove Skutanabb - Kangas, 2009; 37)

Moreover, Jessner (2008) stated that the benefits of multilingualism and multilingual education have been advocated during the last decade. The more languages a person speaks the more chances he/she has to get a wellpaid job and make more money. Indeed, a person with two or more languages will have a wider choice of jobs; it gives him/her additional valuable skills. As companies become more and more international there is a need for multilinguals in media, sales, marketing and customer services. Languages open the door for diversity. While learning a foreign language, a person has an opportunity to study the national character of its native speakers, their costumes and traditions. Furthermore, a multilingual person has an access to different worlds of experience. With a language there come idioms and sayings, folk stories and history, poetry, literature and music, both traditional and contemporary. Reading and writing in more than two languages means that a multilingual person can enjoy literature in original languages.

Besides, research has demonstrated that bi/multilingual education has cognitive, academic, social, and cultural benefits for elementary school students (Cummins, 2000; UNESCO, 1953). At the cognitive level, research in Second Language Acquisition (SLA) has shown that literacy in a child's native language can facilitate learning of an L2. It means children who have access to mother tongue based multilingual education develop better language skills in their mother tongues as well as national languages. When knowledge of a second language (L2) is added to a rich knowledge of a first language (L1), a child forms complex knowledge networks (additive bilingualism) (Cummins, 2000). In contrast, teaching basic skills to young children in a foreign/second language through language immersion is shown to even be detrimental in some cases. Ganschow (1998) stated that Children who have limited vocabulary in their first language will not benefit as thoroughly from bi/multilingual instruction and will use elements of the second language to replace the first (subtractive bilingualism).

At the academic level, bilingual education allows children to access the curriculum and perform better in lower primary schools. Past studies have demonstrated that children learn academic content faster in their L1 than in an unfamiliar foreign language (UNESCO, 1953).

At the social level, bilingual education has the advantage of producing individuals who are often tolerant of other people and cultures (Baker, 2006). For example, many students in bi/multilingual programs interact with their peers who are from different cultural and linguistic backgrounds and learn to depend on each other in order to learn the academic content taught in both languages. Through this interaction, the students improve their social skills and become more tolerant of other people.

\section{Bi/Multilingual Education Program Models}

For about forty year's scholars search for models/programs which are suitable for bi/multilingualism. The program models have been categorized into meaningful categories that highlight broad agreements among researchers, many variations exist in the delivery of each approach (Thomas \& Collier, 2002).

The first general rule according to May (2008) is that programs can be defined as either subtractive or additive. A program is considered subtractive if it promotes monolingual learning in the dominant language, either losing or replacing one language with another, whereas a program can be considered additive if it promotes bilingualism and biliteracy over the long term, usually by adding another language to the student's existing repertoire (May, 2008). Expanding on these definitions, Baker (1993 cited in García, 1997), explains that educational programs that support additive bilingualism are referred to as strong, whereas those which engage in subtractive bilingualism are referred to weak.

Secondly, according to Skutnabb-Kangas (1999), a good educational program accomplishes the following goals from a language and identity perspective: a) high levels of multilingualism, b) a fair chance of achieving academically at school, and developing a strong, positive multicultural identity, and c) positive attitudes towards self and others. The models of bi/multilingual education can be evaluated according to their attainment of these three goals and categorized under weak and strong models as described by Baker (2001), García (1997), and Skutnabb-Kangas (1999).

\section{Strong Models of Bi/Multilingual Education}

Strong models of bilingual education include six of Ball's(2010) approaches, namely: Mother tongue-based instruction (Approach 1), Bilingual education or two-way bilingual education (Approach 2), Mother tongue-based bi/multilingual education or developmental bilingualism (Approach 3), multilingual education (Approach 4), Maintenance bi/multilingual education or additive bilingual education (Approach 6) and Immersion (Approach 7). In these programs the promotion of two or more languages is attempted and the aim is to enrich the child linguistically (Baker, 1996).

According to Skutnabb-Kangas (1999: 187-190) the main principles that make these models effective at accomplishing multilingualism, fair academic achievement and positive multilingual and multicultural identity and attitudes through bilingual education are: 
+ They offer support by using as the main medium of education during the first eight years that language which is least likely to develop to a high formal level. For minority children, this is their own mother tongue. For majority children, it should be a minority language.

+ All children, not only minority children, are to become high-level bilinguals. This is especially important where minority children and majority children are in the same class.

\begin{tabular}{|c|c|c|}
\hline Approach & Name & Description \\
\hline 1 & $\begin{array}{l}\text { Mother Tongue-Based } \\
\text { Instruction }\end{array}$ & The learning programme is delivered entirely in children's L1 \\
\hline 2 & Bilingual Education & $\begin{array}{l}\text { Two languages are used as the media of instruction. This type of } \\
\text { instruction is also known as 'dual language instruction' in which } \\
\text { children who speak both the minority and majority language are taught } \\
\text { in both majority and minority languages. }\end{array}$ \\
\hline 3 & $\begin{array}{l}\text { Mother Tongue-Based } \\
\text { Bi/Multilingual } \\
\text { Education }\end{array}$ & $\begin{array}{l}\text { L1 is used as the primary medium of instruction during all of primary } \\
\text { school. Then, L2 and L3 is introduced as a subject of study to prepare } \\
\text { children for eventual transition to using L2/L3 as the medium of } \\
\text { learning in some academic classes. }\end{array}$ \\
\hline 4 & Multilingual Education & Formal use of more than two languages in the curriculum. \\
\hline 5 & $\begin{array}{l}\text { Transitional } \\
\text { Bi/Multilingual } \\
\text { Education, } \\
\text { 'Bridging' }\end{array}$ & $\begin{array}{l}\text { This type of instruction is aimed at planning a transition for children to } \\
\text { move from learning in L1 to learning in L2. Such transition can be done } \\
\text { abruptly after a few years or after a longer period during which the child } \\
\text { has become fully fluent academically in his/her L1. }\end{array}$ \\
\hline 6 & $\begin{array}{l}\text { Maintenance } \\
\text { Bi/Multilingual } \\
\text { Education }\end{array}$ & $\begin{array}{l}\text { Even after L2 has been introduced, children are instructed in L1 and L2. } \\
\text { L1 continues, often as a subject of study, to ensure ongoing support for } \\
\text { children to become academically proficient in L1. This is also called } \\
\text { 'additive bilingual education' because one or more languages are added } \\
\text { but do not displace L1. }\end{array}$ \\
\hline 7 & $\begin{array}{l}\text { Immersion or Foreign } \\
\text { Language Instruction }\end{array}$ & $\begin{array}{l}\text { The entire education programme is provided in a language that is new } \\
\text { to the child. }\end{array}$ \\
\hline 8 & Submersion & $\begin{array}{l}\text { Speakers of non-dominant languages have no choice but to receive } \\
\text { education in a language they do not understand. The approach promotes } \\
\text { subtractive bilingualism, i.e. learning L2 at the expense of L1. }\end{array}$ \\
\hline
\end{tabular}

Table 1: Language Instruction in Education Systems ${ }^{1}$

+ There must be equality in every area including the status of mother tongues and the roles the languages are accorded in class schedules.

+ Teachers must be bilingual or multilingual. Every child in a school must be able to talk to an adult who speaks the same first language.

+ Both languages have to be used as the medium of instruction in some phase of the children's education.

\section{Weak Models of Bi/Multilingual Education}

Weak models of bilingual education include two of Ball's (2010) approaches: Submersion (Approach 8) and transitional bilingual education (Approach 5). The outcomes of these models include monolingualism in the majority language and assimilation into the mainstream culture, values and attitudes.

\section{i/ Submersion education:}

Submersion education represents the weakest form of bilingual education. It concerns children from language minority homes who are taught immediately through the majority language. According to Baker (2001), there are many problems with this type of education, which includes the following:

+ Both teachers and students will be expected to use only the majority language, not the home language of the child.

+ Considerable variations in students' language ability in a classroom may often create problems in teaching and classroom management for the teacher.

+ There is no reason to assume that children will quickly and effortlessly acquire the majority language skills necessary to cope with the curriculum material.

+ There may also be problems of social and emotional adjustment.

+ The identity of the child, the parents, the home, community and culture appear to be disapproved of, disparaged and discounted. Such a model often denies or denounces their language, their relationships

\footnotetext{
${ }^{1}$ Source: Ball, Jessica. 2011. Mother Tongue-Based Bilingual/Multilingual Education in the Early Years. UNESCO
} 
and often their race.

+ There can be enormous stress: listening to a new language demands high concentration and is tiring with constant pressure to think about the form of language and less time to think about curriculum content because the child has to take in information from different curriculum areas and learn a language at the same time. Submersion education may occur with the addition of withdrawal classes to teach the majority language, but still appears ineffective in producing bilingual children.

\section{ii/ Transitional Bilingual Education}

It is the second weak model and differs from submersion education in that language minority students are initially instructed through their mother tongue until they are thought to be proficient enough in the majority language to cope with mainstream education (Skutnabb-Kangas, 1999).

- Learner's mother tongue is seen as having little or no intrinsic value in society, only an instrumental value.

+ Teaching through the medium of the mother tongue is not seen as a right to which the child in entitled. The mother tongue is seen as useful only in so far as its auxiliary use enhances the knowledge of the dominant language.

$\downarrow$ It encourage dominance and often monolingualism in the majority language.

+ Not supporting the home language and culture, it attempts to discourage children's acceptance of the cultural and linguistic norms of their ethnic group.

\section{Ethiopian Language policy}

The statistical table of 2007 population and housing census of Ethiopia indicates 70 languages are active in the country (but according to Ethnologue the number of language are more than 85), divided among four different language families: the Semitic, Cushitic and Omotic families of the Afro-asiatic phylum, and those belonging to the Nilo-Saharan Phylum. It is the only country south of the Sahara with its own Script called "Ethiopic" which is more than twenty centuries old.

Even if Ethiopia is rich in linguistic diversity the past government considered it as obstacle for our national development and unity. The language policy of Imperial regime and its predecessor was illustrious for promoting a centralized policy in safeguarding its power and running nation building smoothly. It was dominated by the perception which promoted linguistic and cultural homogeneity as the necessary requirements for social and economic progress and political stability. This was an ideological tenet emanated from westerners who strictly considered inherited monolingualism as a gateway to development (Alexander 1996, Ricento 2006). Zelalem (2012) indicates that the language policy of imperial regime favoring the development and expansion of monolingualism (Amharic) and did not give enough attention to develop other languages.

The language planning efforts of Derg shows some progress from its predecessors. It gives equal state recognition to all ethno linguistic groups to use and develop their language and cultures. More than 15 languages were employed for medium of instruction in the literacy campaign. So, it reduced the rate of illiterates and left its trace as a good experience in the use of vernacular languages in education (zelalem 2012).

After the downfall of the Derg regime, the newly formed government (EPRDF) introduced a national educational policy based on the use of 'mother tongues' as the medium of instruction in all public schools. The purpose of Educational policy was to foster national unity, identity, and development while respecting cultural diversity. It creates an opportunities for endogenous languages to serves as the official working language (Afan Oromo, Tigrigna, Somali, Afar, Wolayita, Sidama,) and language of education throughout the region.

According to Lanza and Hirut (2014) the policy of ethnic federalism was mainly introduced to recognize the various ethnolinguistic groups in the country, and the goal of using ethnic/regional languages was to satisfy the diverse needs of Ethiopia's multiethnic and multilingual population.

Today regional and local languages are widely used in the educational, administrative and judiciary systems as well as in the media. As a result, the written form of 28 regional and local languages that were formerly used only in spoken form are now being used in primary education, in official communication, and in the media and the public spheres. Regional governments have developed their languages by creating scripts for them and are preparing teaching materials in them to meet the needs of the national curriculum.

The Oromiya National Regional State recognizes that all languages have equal recognition by the state. The official language of the state is Afan Oromo. Afan Oromo is used in education, administration, justice and the media apart from being the lingua franca in the vast wide areas in the country. In Education, Afan Oromo is used as a medium of instruction in informal education, primary education (up to $2^{\text {nd }}$ cycle), and in the colleges of primary school teachers education at $10+1,10+3$. It is also offered as a subject from grade one up to postgraduate level. Primary school education is also available in Amharic in most of the towns in the Oromiya National Regional State to satisfy the needs of the non-Afan Oromo speaking nationalities. According to Derib and Getachew (2006) efforts are underway to offer primary education in Somali in cooperation with the Somali National Regional state in the border areas of Oromiya that are close the Somali National Regional State. 
In a multilingual country like Ethiopia, it is useful for a citizen to learn at least one additional language for national communications. Due to certain historical circumstance, the language that, in content and distribution, can be of greater service to the country as a common national language is Amharic. At present, Amharic is the working language of the Federal Government as well as some Regions. Thus, Amharic is offered as a subject from Grade 3 or 4 on up. Due to this most of the speakers of regional languages are bilingual in Amharic, a situation that allows the languages to be in extensive and long-term contact.

Moreover, English, the de facto official second language in Ethiopia, is in the equation of language use, alongside the national working language Amharic and the regional languages that have gained status through the policy of ethnic federalism (Lenza and Weldemariam 2014). In addition, English language is important not only for international relations, but because it is also the medium of instruction from secondary school on. For this reason, it is given as a subject from Grade 1 upwards. The reason why English is taught as a subject from the first grade is because the language is not spoken at home and students' only encounter with the language is in school.

\section{Language Attitudes in Ethiopian Context}

Several researchers are conducted on language attitude. But most of studies done in the area of attitudes toward a particular language as MOI, attitudes toward a particular language, how attitudes affect second language learning of them. Here, some of those previous works are reviewed.

As Cohen (2000) conducted a study on use of Amharic and local languages in both rural and urban populations of SNNPR is shaped by their identity and opportunities. Cohen's study indicates that urban and rural populations in SNNPR, Ethiopia do not have the same attitudes toward the use of Amharic and local languages. Cohen's (2000) study reveals that urban populations in SNNPR have favourable attitudes toward the use of Amharic as media of instruction because they thought that Amharic has the ability to provide opportunities. On the contrary, rural populations in general prefer local languages as media of instruction because the opportunities that arise from the use of Amharic are limited in rural environment of SNNPR.

Mequanint (2009) had carried out a study entitled "Attitudes toward Gamotstso as MOI in the First Cycle of Primary Education in Gamo Gofa Zone." The study was aimed at examining the attitudes of students, teachers and parents according to their rural/urban background and evaluating the overall situation of mother tongue education especially in that particular area. The results of the study indicated that students, teachers, and parents had favourable attitudes toward Gamogna as a MOI; they had also very good proficiency in Gamogna and Amharic. Mequanint (2009) had summarised that students and parents did not have negative feelings toward Amharic and/or English to be language of instruction. Finally, Mequanint's study had showed that some teachers had believed that English was the right language to teach some subjects.

Regarding attitudes to second language learning, Alemgena (2008) had done the study entitled 'Attitudes and Motivation of Students Learning Afan Oromo as a Second Language: The Case of Adama Senior Secondary School'. The findings of Alemgena's (2008) study had showed that the majority of the respondents had favourable attitudes toward the speakers of the language. However, they had unfavourable attitudes towards Afan Oromo and its usage. The respondents' instrumental orientation was very strong. The reason for unfavorable attitude is teachers had no positive feelings for second language learners, the content of the text book was beyond their level and native learners were not supportive.

Gashaw (2012) conducted study on Attitudes to Gamogna, Amharic and English Languages in Primary Schools in Arba Minch. His study revealed that the participants of the study had favourable attitudes to the use of Gamogna, Amharic and English in the education system. At the individual level they were also (students and teachers) enthusiastic to be multilingual of Gamogna, Amharic and English. But their degree of enthusiasm was different from language to language. They were most enthusiastic about English then Amharic, and expressed the least favourable attitudes toward Gamogna. Parents preferred their children to be familiar with all of the languages for both instrumental and integrative purposes.

\section{Methodology \\ Research Design}

For multilingual education programs, student attitudes are particularly important because success is dependent on student investment. Perhaps even more importantly, children's attitudes are intrinsically valuable because they allow researchers access to a unique point of view, which is grounded in the temporal nature of childhood (Uprichard, 2008). As a result the purpose of this study is to answer the question: What are student attitudes toward multilingualism? Quite simply, how do students feel about Amharic, Afan Oromo and English? What are the attitudes of the teachers towards the aspects of multilingualism in school? And how parents support the students to learn diverse languages?

In order to answer these questions mixed research approach is taken as a research design. As Dornyei (2007; 45) explain using mixed research approach is preferable in three reasons. First, by using both QUAL and QUAN approaches researchers can bring out the best of both paradigms, thereby combining quantitative and qualitative 
research strengths. Second, we can gain a better understanding of complex phenomenon by converging numeric trends from quantitative data and specific details from qualitative data. Thirdly, it has a potential to produce evidence for validity research outcomes through the convergence \& triangulation of the findings.

\section{Description of Study Area}

This study is conducted to examine students and teachers attitude toward multilingualism in the selected primary school of Bale and West Arsi zone. Bale zone is one of the geographically peripheral provinces in the nation, which is situated in the south eastern part of the country. It is bounded with Somale Regional State in east, East Harerge zone in north east, West Harerge and Arsi zones in north, West Arsi in west, and Guji in south. It has 18 woredas with a total population of $1,402,492$.

West Arsi zone is located in southern part of Ethiopia Based on the 2007 Census conducted by the Central Statistical Agency of Ethiopia (CSA), this zone has a total population of 1,964,038, of whom 973,743 are men and 990,295 women. 272,084 or $13.85 \%$ of population are urban inhabitants. A total of 387,143 households were counted in this zone, which results in an average of 5.01 persons to a household, and 369,533 housing units. It has 13 woredas.

Majority of population live in the two zone are Afan Oromo language speaker and use Amharic as an interethnic communication. In urban areas the number of non Afan Oromo speakers is not small. That is the reason why in the selected cities we have get at list one Amharic medium school which serve minority populations (minority in this context refer small in number or non-Afan Oromo speakers).

\section{Sampling Techniques}

For the purpose of this study, eight full cycle primary school in Goba, Robe, Shashemene and Ginir town were selected as the site of interest due to the presence of multilingual and multicultural communities. From the four town, two full cycle primary school from each (one Amharic or bilingual school and one Afan Oromo medium of instruction school) were selected by using purposive sampling. For that reason Madda Walabu and Zeybela primary school from Robe town; Harewa Sinja and Urji Berisa primary school from Goba; Xurge and Mekuria Tessema primary school from Ginir; and Biherawi and Burka Gudina primary school from Shashemene were selected as a sample school. From the eight school Mekuria Tessema, Madda Walabu and Harewa sinja were Afan Oromo MOI, whereas the remaining schools were bilingual which serve both Afan Oromo and Amharic MOI students with two shifts.

In addition, the researchers want to maintain confidence level of 95\% (which means a margin of error/error tolerance of 0.05). To make it clear, as to Dornyei (2007) confidence interval ranges between 0 and 1, therefore 10.95 is equals to 0.05 which is confidence interval (margin of error). Regarding the total populations of the eight schools have 17,380 students and 391 of them selected using simple random sampling using Yemane (1967) formula:

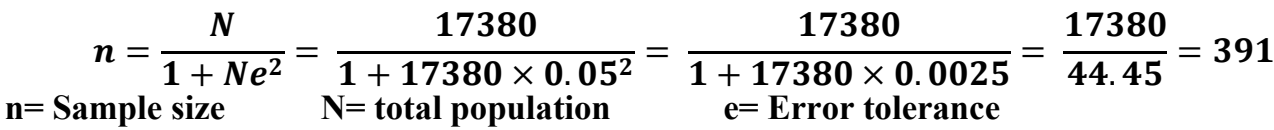

Therefore, 391 students of grade 7 and 8 were randomly selected from the total population of 17,380 from eight primary schools of the two zones under the study in support of quota sampling in order to give equal representation (Gender, grade level and students medium of instruction).

In line with this 48 teachers were selected for questionnaire survey through purposive and availability sampling. The data obtained from 45 teachers were include in the data analysis but the information's of three respondents' were disqualified. Communities' (parents) are the one who have role in students learning. So, 16 parents are selected for face to face interview based on their participation in the school.

\section{Data Collection Instruments}

In order to understand student, teachers and parents attitudes toward multilingual education four data collection tools were employed.

\section{Questionnaire}

The quantitative data was collected using a questionnaire from 391 students and 45 teachers. The reliability test was carried out before its implementation by translating into local languages (Afan Oromo and Amharic) in order to get consistent results. The instruments developed for students have three sections. The first one focus on background information about the participants, the second about their language attitudes (towards second language i.e either Amharic or Afan Oromo, towards multilingualism, towards foreign language - English) and the third their views on language learning and major challenges. Teachers' questionnaire survey have similar with students in some parts. But it include additional questions which need teacher personal view on their teaching method employed in the classroom in fulfilling the needs of second language learners. 


\section{Individual Interviews}

The individual interviews provided a better understanding of specific viewpoints of parents perspective to multilingualism. While a set of questions guide the interviews, the format was flow in a less structured way that allowed the conversation to move easily between topics. So, 16 community members ( 2 from each school) were selected for face to face interview. We used Afan Oromo and Amharic as a media of instruction. Some of parent interviews were conducted in the village while the rest were conducted in the school grounds.

\section{Focus Group Discussion}

The focus group method was selected because it allows for discovery of a range of opinions over several groups. As Krueger and Casey $(2009 ; 7)$ suggest, "the focus group presents a more natural environment than that of an individual interview because participants are influencing and influenced by others - just as they are in life". Since a goal of this study was to understand the viewpoints of teachers, students and parents within eight primary school of Goba, Ginir, Shashemene and Robe towns, it was natural to engage them in group conversations about their beliefs and levels of support. In line with this, eight focus groups were conducted with teachers in the selected schools. A minimum of three and a maximum of seven teachers were participated in each focus group. Participants of focus group discussion were those who participate in the questionnaire survey. The teachers were encouraged to use any language which can express their ideas better.

\section{Data Collection Procedures}

The necessary and important steps have made by the researchers in the pre-administration processes. First, the researchers gave cooperation request formal letter written from MWU Research and Publication Directorate to the selected City education office. Second, the City administration education office written back letters to all schools that request necessary cooperation as an indication of permission. Third, list of Grade 7 and 8 students' were collected from unit leader. Fourth, through the above mentioned sampling technique students were identified from each class.

In the administration time, already selected participants were called to library room and made to sit in accordance to their grade level. After that, the questionnaires were dispatched to students and then all necessary orientations were given. This administration processes were made through the help of school directors/vice and research assistants. At the end all data were administered at the same time during the regular class in consideration of their study time.

Teachers' questionnaires were given out during a morning/afternoon tea session in the staff room. The researcher used 5-8 minutes of this time to elaborate on the research project and the questionnaires. Later on FGD and interviews were conducted with language subject teachers and parents (by arranging program with students to call their parents who are active participate in the school activities in guide of school directors and assistants).

\section{Method of Data Analysis}

Data analysis refers to "summarizing, organizing, shifting and synthesizing the data to arrive at the results and conclusions of the research" (Seliger \& Shohamy, 1989: 62). Therefore, data collected from the mentioned sources were finally categorize and tabulate according to their similarity. Presentations, descriptions, interpretations of the raw data, and connections of the raw data with literature are the procedures that the researchers followed during data analysis. Depending on the nature of the data, qualitative and quantitative methods of data analysis were employed. Qualitative method of data analysis used to analysis "a subjective opinion, experiences and feelings of individuals and thus the explicit goal is to explore the participants' views of the situation being studied" (Dörnyei, 2007:38). Dörnyei (2007:33) also defines quantitative method of data analysis as "it centered on the study of variables, which are quantified by counting [through numbers], scaling, or by assigning values to categorical data." Generally, "mixed (qualitative and quantitative) method of analysis involves different combinations of qualitative and quantitative research either at the data collection or at the analysis levels" (Dörnyei, 2007:24). The data collect from interview and focus group discussion was qualitatively analyzed. However, questionnaires are analyzed quantitatively and qualitatively. Descriptive and inferential statistics comprises of mode, median, means (M), and standard deviation (SD) were computed to see the scores distribution.

In applied linguistics research comparing various groups of people is the most common statistical procedure (Lazaraton 2005). So, the Independent sample t-test helps us to compare the result of Afan Oromo speaker and non-Afan Oromo speaker as well as gender difference regarding their attitude. In addition partial correlation between the three variables (students' attitude to Afan Oromo/Amharic, attitude of English language and attitude to Multilingualism) were calculated.

\section{DATA ANALYSIS AND INTERPRETATIONS}

As already mentioned, the purpose of this study was examining students and teachers attitude towards multilingualism in primary schools of Bale and West Arsi zone. In order to achieve the stated objectives primary 
data was gathered from 391 students, 45 language teachers and 16 parents through questionnaire survey, focus group discussion and interview. The questionnaire survey prepared for students organized in to - background information about the participants, students' commitment and motivation to learn second language i.e Amharic or Afan Oromo, students attitude to English language, students interest to learn diverse language and the final part ask the challenges in their language learning. Teachers' questionnaire organized in three parts. The first one focused on teacher's background information, the second talk about teachers' attitude about multilingualism and the final part ask teachers opinion about their teaching methods towards attaining the need of second language learners.

Data collected from the aforementioned participants were presented in tables and followed by description and interpretations with the support of qualitative data gathered by interview and focus group discussions. This chapter organized into five main topic; background information of participants; students' attitude to multilingualism; teachers' attitude and practices of multilingual education; challenges in second and foreign language learning; and parents support in students' language learning.

\section{Background information of Respondents}

The main respondents of this study were students, teachers and parents. As indicated in Table 2 the number of Female $(\mathrm{n}=193,49.4 \%)$ and Male $(\mathrm{n}=198.50 .6 \%)$ respondents included in the study were relatively equal. The same to gender, students grade level $(52.7 \%$ from Grade 7 and $47.3 \%$ were Grade 8 ) and medium of instruction (50.4 \% who taught in Amharic and $49.6 \%$ were Afan Oromo) get equivalent representations in the sample distributions. This was done purposively by the researchers to compare their mean difference and to show the significance of gender, mother tongue and medium of instruction on respondents' attitude to multilingualism. In addition the numbers of students selected from each school were relatively equal.

Majority of student respondents age was between $11-15(\mathrm{n}=293,74.9 \%)$. As a result of their residence $(95.9 \%$ of them from Urban) most of students were enrolled in grade 1 less than at the age of 7 . This corresponds with the standard of ministry of educations. The big difference observed on students mother tongue (Amharic $\mathrm{n}=207$, $52.9 \%$; Afan Oromo - $\mathrm{n}=145,37.1 \%$; Both Amharic and Afan Oromo- $\mathrm{n}=35,9 \%$ and the remaining scored others like Tigrigna, Somali, Gamo and Wolayita).

Table 2:- Background information of students

\begin{tabular}{|c|c|c|c|c|c|c|c|c|c|c|c|}
\hline & \multicolumn{9}{|c|}{ Name of School } & \multirow[b]{2}{*}{$\%$} \\
\hline & & Turge & $\begin{array}{l}\text { Mekuria } \\
\text { Tessema } \\
\end{array}$ & Zeybela & $\begin{array}{l}\text { Medda } \\
\text { Walabu } \\
\end{array}$ & $\begin{array}{l}\text { Urji } \\
\text { Berisa }\end{array}$ & $\begin{array}{l}\text { Harewa } \\
\text { Sinja } \\
\end{array}$ & $\begin{array}{l}\text { Burka } \\
\text { Gudna } \\
\end{array}$ & Biherawi & Total & \\
\hline \multirow[b]{2}{*}{ Sex } & Male & 15 & 26 & 19 & 26 & 24 & 24 & 40 & 24 & 198 & 50.6 \\
\hline & Female & 36 & 22 & 21 & 25 & 23 & 23 & 16 & 27 & 193 & 49.4 \\
\hline \multirow[t]{3}{*}{ Age } & $11-15$ & 43 & 41 & 33 & 40 & 33 & 42 & 25 & 36 & 293 & 74.9 \\
\hline & $16-20$ & 7 & 7 & 7 & 11 & 14 & 5 & 31 & 13 & 95 & 24.3 \\
\hline & No Response & 1 & & & & & & & 2 & 3 & 0.8 \\
\hline \multirow{2}{*}{ Residence } & Urban & 49 & 47 & 38 & 50 & 46 & 46 & 49 & 50 & 375 & 95.9 \\
\hline & Rural & 2 & 1 & 2 & 1 & 1 & 1 & 7 & 1 & 16 & 4.1 \\
\hline \multirow[t]{2}{*}{ Grade } & $7^{7^{t h}}$ & 28 & 24 & 21 & 23 & 24 & 24 & 32 & 30 & 206 & $\begin{array}{c}52.7 \\
\end{array}$ \\
\hline & $8^{\text {th }}$ & 23 & 24 & 19 & 28 & 23 & 23 & 24 & 21 & 185 & 47.3 \\
\hline \multirow[t]{2}{*}{ MOI } & Afan Oromo & 0 & 48 & 0 & 51 & 0 & 47 & 25 & 23 & 194 & 499.6 \\
\hline & Amharic & 51 & 0 & 40 & 0 & 47 & 0 & 31 & 28 & 197 & 50.4 \\
\hline \multirow{4}{*}{$\begin{array}{l}\text { Mother } \\
\text { Tongue }\end{array}$} & Afan Oromo & 0 & 32 & 0 & 48 & 0 & 31 & 23 & 11 & 145 & 37.1 \\
\hline & Amharic & 49 & 11 & 36 & 1 & 45 & 8 & 29 & 28 & 207 & 52.9 \\
\hline & Both $A F / A M$ & 2 & 4 & 2 & 2 & 2 & 8 & 3 & 12 & 35 & 9.0 \\
\hline & Other & & 1 & 2 & & & & 1 & & 4 & 1 \\
\hline \multirow{4}{*}{$\begin{array}{c}\text { Home } \\
\text { Language }\end{array}$} & Afan Oromo & 3 & 33 & 0 & 43 & 0 & 25 & 17 & 12 & 133 & 34 \\
\hline & Amharic & 43 & 7 & 33 & 1 & 43 & 5 & 33 & 29 & 194 & 49.6 \\
\hline & Both $A F / A M$ & 5 & 7 & 7 & 7 & 4 & 17 & 5 & 10 & 62 & 15.9 \\
\hline & Other & & 1 & & & & & 1 & & 2 & 0.5 \\
\hline \multirow{3}{*}{$\begin{array}{c}\text { School } \\
\text { Language }\end{array}$} & Afan Oromo & 2 & 33 & 0 & 38 & 0 & 29 & 17 & 15 & 134 & 34.3 \\
\hline & Amharic & 42 & 1 & 27 & 1 & 43 & 0 & 25 & 28 & 167 & 42.2 \\
\hline & Both $A F / A M$ & 7 & 14 & 13 & 12 & 4 & 18 & 14 & 10 & 92 & 23.5 \\
\hline \multirow{4}{*}{$\begin{array}{c}\text { Father } \\
\text { Educational } \\
\text { Status }\end{array}$} & Illiterate & 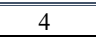 & 2 & 2 & 8 & 8 & 2 & 11 & 11 & 48 & 12.3 \\
\hline & Elementary & 18 & 24 & 9 & 29 & 17 & 16 & 28 & 19 & 160 & 40.9 \\
\hline & Secondary & 14 & 15 & 18 & 10 & 12 & 17 & 9 & 8 & 103 & 26.3 \\
\hline & College/ Univ & 15 & 7 & 11 & 4 & 10 & 12 & 8 & 13 & 80 & 205 \\
\hline \multirow{4}{*}{$\begin{array}{c}\text { Mother } \\
\text { Educational } \\
\text { Status }\end{array}$} & Illiterate & 10 & 5 & 7 & 14 & 12 & 6 & 22 & 22 & 98 & 25.1 \\
\hline & Elementary & 23 & 29 & 16 & 28 & 18 & 21 & 21 & 14 & 170 & 43.5 \\
\hline & Secondary & 11 & 12 & 9 & 8 & 14 & 13 & 10 & 12 & 89 & 22.8 \\
\hline & College/Univ & 7 & 2 & 8 & 1 & 3 & 7 & 3 & 3 & 34 & 8.7 \\
\hline \multirow{2}{*}{\multicolumn{2}{|c|}{ Total }} & 51 & 48 & 40 & 51 & 47 & 47 & 56 & 51 & 391 & \\
\hline & & $13.0 \%$ & $12.3 \%$ & $10.2 \%$ & $13.0 \%$ & $12.0 \%$ & $12.0 \%$ & $14.3 \%$ & $13.0 \%$ & & $100 \%$ \\
\hline
\end{tabular}

This gap was resulted due to a significant number of students selected from Mekuria Tesema ( $\mathrm{n}=15,31.25 \%)$ and Harewa Sinja $(\mathrm{n}=16,34 \%)$ primary school respond either Amharic or both Amharic and Afan Oromo as their mother tongue. Basically these schools were Afan Oromo monolingual schools (Which teach students only in Afan Oromo). This was an indicator to have positive attitude towards the language. This shows the instrumental function 
of Afan Oromo for non-Afan Oromo speaker. Even if their right to learn in mother tongue was recognized by regional state they prefer to learn in Afan Oromo in order to get government jobs in the region after graduation. Regarding on respondents home language 34\%, 49.6\% and 15.9\% of students respond Afan Oromo, Amharic and both Afan Oromo and Amharic respectively. When we compare number of students home language and school language; the number of students who use both Amharic and Afan Oromo in school (for instructional purpose and interpersonal communication with teachers and students) increased (23.5\%) and only Amharic speaker decreased (42.2\%); but there was no big difference observed on Afan Oromo speakers $(34.3 \%)$. On the other hand the majority of students families ( $68 \%$ of mother and $53 \%$ of fathers) not proceed their education beyond elementary. This indicates families support for their students will be limited to fulfilling financial support than academic maters. Table 3 - Teachers background information

\begin{tabular}{|c|c|c|c|c|c|c|c|c|c|c|}
\hline & \multicolumn{9}{|c|}{ Name of School } \\
\hline & & Turge & $\begin{array}{l}\text { Mekuriya } \\
\text { Tessema }\end{array}$ & Zeybela & $\begin{array}{l}\text { Medda } \\
\text { Walabu }\end{array}$ & $\begin{array}{l}\text { Urji } \\
\text { Berisa }\end{array}$ & $\begin{array}{l}\text { Harawa } \\
\text { Sinja }\end{array}$ & $\begin{array}{l}\text { Burka } \\
\text { Gudina }\end{array}$ & Biherawi & Total \\
\hline \multirow[b]{2}{*}{ Gender } & Male & 6 & 2 & 3 & 1 & 1 & 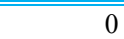 & 1 & 2 & 16 \\
\hline & Female & 1 & 3 & 4 & 7 & 4 & 4 & 4 & 3 & 30 \\
\hline \multirow[b]{2}{*}{ Residence } & Urban & 5 & 4 & 7 & 8 & $\overline{5}$ & 4 & $\overline{5}$ & 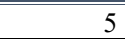 & 43 \\
\hline & Rural & 2 & 1 & 0 & 0 & & & & & 3 \\
\hline \multirow{3}{*}{$\begin{array}{l}\text { Mother } \\
\text { Tongue }\end{array}$} & Afan Oromo & 2 & 2 & 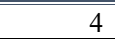 & 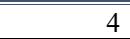 & 2 & 1 & 2 & 2 & 19 \\
\hline & Amharic & 5 & 2 & 3 & 2 & 3 & 3 & 2 & 3 & 23 \\
\hline & $\begin{array}{l}\text { Both } \\
\text { AF/AM }\end{array}$ & & 1 & 0 & 2 & & & 1 & & 4 \\
\hline \multirow{3}{*}{$\begin{array}{c}\text { Home } \\
\text { Language }\end{array}$} & Afan Oromo & 2 & 2 & 1 & 4 & 1 & 2 & 2 & 2 & 16 \\
\hline & Amharic & 3 & 2 & 4 & 2 & 3 & 2 & 1 & 1 & 18 \\
\hline & $\begin{array}{l}\text { Both } \\
A F / A M\end{array}$ & 2 & 1 & 2 & 2 & 1 & & 2 & 2 & 12 \\
\hline \multirow{3}{*}{$\begin{array}{l}\text { Language } \\
\text { teaching }\end{array}$} & Afan Oromo & 2 & 3 & 3 & 4 & 0 & 0 & 3 & 1 & 16 \\
\hline & Amharic & 2 & 2 & 2 & 1 & 4 & 2 & 2 & 1 & 16 \\
\hline & English & 3 & 0 & 2 & 3 & 1 & 2 & 0 & 3 & 14 \\
\hline \multirow{4}{*}{$\begin{array}{l}\text { Teaching } \\
\text { experience } \\
\text { in year }\end{array}$} & $1-5$ & 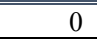 & 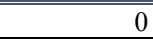 & 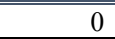 & 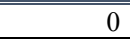 & & 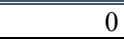 & 1 & 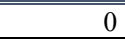 & 1 \\
\hline & $6-10$ & 1 & 0 & 0 & 1 & - & 0 & 0 & 1 & 3 \\
\hline & $11-15$ & - & 1 & 0 & 3 & - & 1 & 2 & 1 & 8 \\
\hline & Above 16 & 6 & 4 & 7 & 4 & 5 & 3 & 2 & 3 & 34 \\
\hline \multicolumn{10}{|c|}{ Grand Total } & 48 \\
\hline
\end{tabular}

As indicated in table 3 almost all of respondents' live in urban (93.4\%). $50 \%$ and $41.3 \%$ of teachers were scored Amharic and Afan Oromo as their mother tongue, the remaining 9.7\% were bilingual in both Amharic and Afan Oromo. Even if who scored both Afan Oromo and Amharic as their mother tongue was small (9.7\%), but in their home $26.1 \%$ of the respondents use both language to communicate with their families and friends. $34.8 \%$ and $39.1 \%$ of teachers use Afan Oromo and Amharic respectively. On the other hand all language teachers (Afan Oromo, Amharic and English) are represented in the study almost equally (34.8\%, 34.8\% and 30.4\%). Surprisingly, $73.9 \%$ teachers who involved in the study have above 16 years of teaching experience. Next to it $17.4 \%$ were grouped under the teaching experience of 11-15. The same to experience, majority of respondents' $(65.2 \%)$ were female and $34.8 \%$ scored male.

\section{Students attitude to Multilingualism}

Descriptive Statistics of total scores of the respondents through variables

Table 4 Median, Mean and Standard Deviation of the students total scores in the three variables

\begin{tabular}{|c|c|c|c|c|c|c|c|c|}
\hline & \multirow[t]{2}{*}{$\mathrm{N}$} & \multirow[t]{2}{*}{ Median } & \multirow[t]{2}{*}{ Mode } & \multirow{2}{*}{$\begin{array}{l}\text { Standardized } \\
\text { Median }\end{array}$} & \multirow[t]{2}{*}{$\mathrm{M}$} & \multicolumn{2}{|c|}{ Range } & \multirow[t]{2}{*}{ SD } \\
\hline & & & & & & Min & Max & \\
\hline ASL & 391 & 3.81 & 4.00 & 3.00 & 3.85 & 1.86 & 5.00 & .53387 \\
\hline AEL & 391 & 3.80 & 4.00 & 3.00 & 3.78 & 1.00 & 5.00 & .69064 \\
\hline AML & 391 & 4.17 & 4.33 & 3.00 & 4.13 & 2.31 & 5.00 & .52904 \\
\hline
\end{tabular}

As indicated in Table 4 the students mean score were above the expected or standardized median of the instruments in attitude towards second language/Amharic or Afan Oromo, attitude towards English language and attitude towards Multilingualism (3.00) by $(0.85,0.75$ and 1.13$)$ respectively. This implies that the students' average scored is above the standardized mean of the total scale (expected standardized mean) or the respondents have favorable attitude to learn Amharic/Afan Oromo, English and to become multilingual. Scores of all variables were shown great difference between expected median and mean scores of participants. But scores of attitude towards English were averagely spread out widely among the participants at all score levels (ranging from 1:005:00, $\mathrm{SD}=0.69$ ). Therefore, attitude on English language indicates relatively more variability differences. 
Independent Sample t-test on Gender, Mother tongue and Medium of Instruction

Table 5- Independent Sample t- test in the three Variables; (ASL, AEL, and AML)

\begin{tabular}{|c|c|c|c|c|c|c|c|c|}
\hline No & Variable & & Male & Female & $\begin{array}{c}\text { Afan } \\
\text { Oromo }\end{array}$ & Amharic & $\begin{array}{l}\text { Afan } \\
\text { MOI }\end{array}$ & $\begin{array}{l}\text { Amharic } \\
\text { MOI }\end{array}$ \\
\hline \multirow{5}{*}{1} & \multirow{5}{*}{ ASL } & $\mathrm{N}$ & 198 & 193 & 145 & 207 & 194 & 197 \\
\hline & & $\mathrm{M}$ & 3.83 & 3.87 & 3.64 & 4.00 & 3.67 & 4.02 \\
\hline & & SD & 0.56 & 0.50 & 0.51 & 0.50 & 0.50 & 0.50 \\
\hline & & t-test & \multicolumn{2}{|c|}{-0.686} & \multicolumn{2}{|c|}{-6.527} & \multicolumn{2}{|c|}{-6.915} \\
\hline & & Sig & \multicolumn{2}{|c|}{0.493} & \multicolumn{2}{|c|}{.000} & \multicolumn{2}{|c|}{.000} \\
\hline \multirow{4}{*}{2} & \multirow{4}{*}{ AEL } & $\mathrm{M}$ & 3.74 & 3.82 & 3.62 & 3.92 & 3.57 & 3.98 \\
\hline & & SD & 0.71 & 0.66 & 0.73 & 0.63 & 0.72 & 0.58 \\
\hline & & t-test & \multicolumn{2}{|c|}{-1.170} & \multicolumn{2}{|c|}{-4.066} & \multicolumn{2}{|c|}{-6.105} \\
\hline & & Sig & \multicolumn{2}{|c|}{0.243} & \multicolumn{2}{|c|}{.000} & \multicolumn{2}{|c|}{.000} \\
\hline \multirow{4}{*}{3} & \multirow{4}{*}{ AML } & $\mathrm{M}$ & 4.11 & 4.15 & 4.13 & 4.11 & 4.18 & 4.08 \\
\hline & & SD & 0.50 & 0.55 & 0.56 & 0.50 & 0.55 & 0.50 \\
\hline & & t-test & -0.759 & 0.93 & 1.75 & & & \\
\hline & & Sig & \multicolumn{2}{|c|}{0.45} & \multicolumn{2}{|c|}{0.69} & \multicolumn{2}{|c|}{0.81} \\
\hline
\end{tabular}

Alpha level $* 0.05, d f=389, N=391$ (350 and 352 for mother tongue respectively), 2-tailed

Male respondents $(\mathrm{N}=198)$ were associated with numerically less favorable attitude to English language $(\mathrm{M}=3.74, \mathrm{SD}=0.71)$ than female respondents $(\mathrm{M}=3.82, \mathrm{SD}=0.66)$. Moreover, Afan Oromo mother tongue and MOI respondents' scored small mean score in learning second language (Amharic) and attitude to English language $(\mathrm{M}=3.64$ and $3.67 ; \mathrm{SD}=0.51$, and 0.73$)$ respectively compared with Amharic mother tongue and MOI respondents . To test the hypothesis that male and female, Afan Oromo and Amharic mother tongue, Afan Oromo MOI and Amharic MOI respondents were associated with statistically significantly different in attitude to second language, English language and multilingualism, an independent sample t-test was performed.

As can be seen in table 5 the results of t-test reveals that the mean score difference of the three variables were not shown statistically significant in gender of respondents. The $t$ value of attitude to second language, attitude to English language and attitude to multilingualism in gender were $(-0.686,-1.170$ and -0.759$)$ respectively. The p-value is greater than the critical value ( 0.05 level of significance).

But students' attitude to second and English language show statistically significant in mother tongue and MOI of respondents' difference. The t-value of ASL and AEL in mother tongue were $(-6.527,-4.066 \mathrm{p}=.00)$ and MOI ($6.915,-6.105 \mathrm{p}=.00)$ respectively. This implies the Afan Oromo mother tongue and MOI respondents have less favorable attitude than Amharic mother tongue and MOI respondents' in learning their second language as well as English language. Here we have to understand that both group have positive attitude to both languages.

Respondents' attitude to multilingualism were not statistically significant on respondent's mother tongue and MOI with t-value of 0.94 and 1.74 with $\mathrm{p}=0.69,0.81$ respectively. This implies attitude to multilingualism wasn't statistically associated with mother tongue and medium of instruction.

Pearson's Product Moment Correlation Coefficient between the variables

Table 6- The Correlation between Second Language attitude and Attitude to Multilingualism

\begin{tabular}{|l|c|c|c|c|c|}
\hline Pearson correlation & \multicolumn{5}{|c|}{ Attitude to Multilingualism } \\
\hline $\begin{array}{l}\text { Attitude to Second } \\
\text { Language }\end{array}$ & rxy & $\mathrm{r}^{2}$ & $\%$ & Standardized Coefficients & $\mathrm{df}$ \\
\cline { 2 - 6 } & \multirow{2}{*}{$0.441^{* *}$} & 0.194 & 19.4 & Beta & 389 \\
\cline { 4 - 6 }
\end{tabular}

**. Correlation is significant at the 0.01 level of significance, 2 -tailed.

Predictors: Attitude to second Language scores

Dependent Variable: Attitude to Multilingualism Scores

Looking on the table 6, the selected primary schools of Bale and west Arsi zone students' attitude to their second language /Amharic or Afan Oromo and attitude to multilingualism were positively, moderately and significantly correlated at significance level of 0.01 . The two variables were positively and significantly related as $\mathrm{r}=0.441$. As the coefficient determination described the relationship of variables accounted for $19.4 \%$. Thus, their attitude to Amharic/Afan Oromo explains $19.4 \%$ of the variance in attitude to multilingualism, and vice versa. This also means that $80.6 \%$ of the variance is unaccounted or it is accounted by other variables. 
Table 7 - The Correlation between Attitude of English Language and Attitude to Multilingualism

\begin{tabular}{|l|c|c|c|c|c|}
\hline Pearson correlation & \multicolumn{5}{|c|}{ Attitude to Multilingualism } \\
\hline $\begin{array}{l}\text { Attitude to English } \\
\text { Language }\end{array}$ & rxy & $\mathrm{r}^{2}$ & $\%$ & Standardized Coefficients & Df \\
\cline { 2 - 5 } & & & & Beta & 389 \\
\cline { 2 - 5 } & $0.275^{* *}$ & 0.076 & 7.6 & 0.275 & \\
\hline
\end{tabular}

**. Correlation is significant at the 0.01 level of significance, 2-tailed.

Predictors: Attitude to English Language scores

Dependent Variable: Attitude to Multilingualism Scores

As examined in table 4.2, positive, weak but significant correlation were found between attitude to English language and attitude to multilingualism $(r=0.275, p<.01)$. The two variables positively and significantly associated in coefficient determination of $\mathrm{r}=0.076$. Attitude to English language can enlightens the variance of attitude to multilingualism by $7.6 \%$ and the reverse is true.

Table 8- The Correlation between Attitude to English and Second Language Learning

\begin{tabular}{|l|c|c|c|c|c|}
\hline Pearson correlation & \multicolumn{5}{|c|}{ Attitude to Second Language Learning } \\
\hline Attitude to English Language & $\mathrm{rx} 1 \mathrm{rx} 2$ & $\mathrm{r}^{2}$ & $\%$ & Standardized Coefficients & Df \\
\cline { 2 - 5 } & & & & Beta & 389 \\
\cline { 5 - 6 } & $0.384^{* *}$ & 0.147 & 14.7 & 0.384 & \\
\hline
\end{tabular}

**. Correlation is significant at the 0.01 level of significance, 2-tailed.

$\mathrm{X} 1=$ dependent variable of attitude to English Language

$\mathrm{X} 2=$ dependent variables of attitude to Second language learning

Table 8 describes the Pearson correlation between the attitude to English and attitude to Amharic/Afan Oromo. Analysis of this inference come across the positive and moderate coefficient and significant of the Pearson correlation $(\mathrm{r}=0.384, \mathrm{P}<0.01)$, the Pearson correlation accounted for $\mathrm{r}$ square of 0.147 . This leads to the conclusion of the relationship between attitude to English and attitude to Amharic/Afan Oromo may explained each other to both direction by $14.7 \%$ of confidence. As a result, it is possible to say that moderate, positive relationship between attitude to English and attitude to Amharic/Afan Oromo discovered in selected primary school of Bale and west Arsi zone students.

Partial correlation between variables

Table 9 - Effects of independent variables (ASL \& AEL) to predict dependent variable (AML) in control of respondents Gender, Mother tongue, MOI

\begin{tabular}{|c|c|c|c|c|c|c|}
\hline Correlation & \multicolumn{6}{|c|}{ Attitude of Multilingualism } \\
\hline & $\mathrm{R}$ & $\mathrm{R}^{2}$ & $\%$ & $\begin{array}{l}\% \text { of Simple } \\
\text { correlation }\end{array}$ & $\mathrm{D} / \mathrm{ce}$ & Sig \\
\hline English Langue & 0.318 & 0.101 & $10.1 \%$ & $7.6 \%$ & $2.5 \%$ & 0.00 \\
\hline Second Language & 0.498 & 0.248 & $24.8 \%$ & $19.4 \%$ & $5.4 \%$ & 0.00 \\
\hline
\end{tabular}

Table 9 explores the relationship between two variables, while statistically controlling for the effect of variable (respondents' gender, mother tongue and medium of instructions) that might be influencing the relationship. As it is shown, attitude to English language can predict attitude to multilingualism positively and significantly $(\mathrm{R}=0.318, \mathrm{p}<0.05)$. This means attitude to English can predict attitude to multilingualism by $10.1 \%$ of confidence if the above variables keep constant.

Similar to this, attitude to Amharic/Afan Oromo and attitude to multilingualism were correlated positively and significantly $(\mathrm{R}=0.498, \mathrm{P}<0.05)$. Hence, large proportion of variance in the attitude of multilingualism accounted for using attitude to Amharic/Afan Oromo predict $(\mathrm{R}=0.248)$. If compared, attitude to Amharic/Afan Oromo can predict attitude to multilingualism better than attitude of English language $(24.8 \% \%$ and $10.1 \%$ respectively) under control of the students' gender, mother tongue and medium of instruction they were involved. Both variables were significant predictor of Bale and West Arsi zone primary school students' attitude to multilingualism considering the above variables constant (Sig-0.00 P $<0.05$ ). An inspection of the Pearson correlation $(A S L=0.441, \mathrm{AEL}=0.275)$ with attitude to multilingualism suggested that controlling for the above variables responding has no significant effect on the strength of the relationship between these computed variables except attitude to second language learning/Amharic or Afan Oromo $(A E L=0.318, \mathrm{ASL}=0.498)$.

Table10 - students' Language in their second language

\begin{tabular}{|l|r|r|r|r|r|}
\hline & $\mathrm{N}$ & Minimum & Maximum & Mean & \multicolumn{1}{|c|}{ Std. Deviation } \\
\hline Proficiency on Amharic & 144 & 1.00 & 4.00 & 2.15 & .905 \\
Proficiency on Afan Oromo & 207 & 1.00 & 4.00 & 2.49 & 1.013 \\
\hline
\end{tabular}


As we have observed in table 4 the students mean score of attitude to second language learning was high. In other word, the student respondents show positive attitude to learn Amharic and Afan Oromo. Even if they score high mean in the attitudinal survey; majority of respondents admit their poor communicative skill of the language. As indicated in in table the mean score of respondents in Amharic $(\mathrm{M}=2.15)$ and Afan Oromo (2.49) was below average mean score. This shows a contradictions with previous research finding. Because attitudes are related strongly to motivation, and motivated students develop positive views about a language because of high achievement 'whereas relatively unsuccessful learners might acquire negative attitudes. According to Wilhelm (1999) it is evident that people with a negative attitude towards a language could not be motivated learners, and there is evidence to support the correlation between the positive attitude about a language and high achievement. As a result of this, it was important to dig out challenges that contribute for the poor language skills of students (it was discussed in 4.4).

Teachers attitude to Multilingualism Table 11 - Descriptive statistics of teachers total scores of attitude to multilingualism

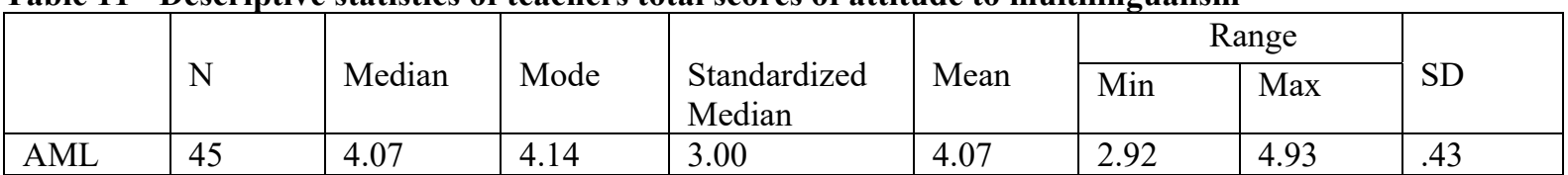

The mean score of teachers' attitude to multilingualism were greater than the expected median of instrument by 1.07. This indicates that teachers have favorable attitude to be speakers of diverse languages. Their mean score of attitude to multilingual scale show less variability difference. Because the difference between respondents' minimum score and expected median were only 0.08 and majority of respondents' score were above the standardized median.

Table 12- Independent Sample t- test in teachers' attitude to Multilingualism

\begin{tabular}{|l|l|l|c|c|c|c|}
\hline No & Variable & & Male & Female & Afan Oromo & Amharic \\
\hline \multirow{3}{*}{1} & \multirow{2}{*}{ AML } & $\mathrm{N}$ & 15 & 30 & 18 & 23 \\
\cline { 3 - 7 } & & $\mathrm{M}$ & 4.1467 & 4.0387 & 4.1541 & 4.0171 \\
\cline { 3 - 7 } & & SD & 0.42348 & 0.42919 & 0.41464 & 0.46792 \\
\cline { 3 - 7 } & t-test & \multicolumn{2}{|c|}{-0.80} & \multicolumn{2}{c|}{0.977} \\
\cline { 3 - 7 } & Sig & \multicolumn{2}{|c|}{0.428} & \multicolumn{2}{c}{0.334} \\
\hline
\end{tabular}

Alpha level $*<0.05, \mathrm{df}=43, \mathrm{~N}=45,2$-tailed

As indicates in table the independent sample t-test in teachers' attitude to multilingualism were not statistically significant on respondent's gender and mother tongue with t-value of 0.80 and $0.977 ; p=0.42,0.33$ respectively. The significance level shows greater than the critical p value ( 0.05 level of significance). This implies teachers' gender and mother tongue doesn't show any difference on their attitude to multilingualism.

\section{Practices of Multilingualism in the classroom}

According to Cook (1996), the role of language teachers refers to the way learners are treated; this includes the language used by the teacher, the attitudes of the teachers towards the language and the learners, the methods and materials used, or the environment where the language is used. If teachers cannot handle the language adequately in the classroom and they are not motivated and enthusiastic towards the target language, then, it is very likely that their students will fail and they will adopt a negative attitude for the particular language for the rest of their life. Regarding on this issue, all of teacher respondents believe that they are employing diverse teaching methods to increase their students' participation and to develop positive attitude for the language. The following methods were frequently mentioned by most teachers: debating, questions and answers, report writing, life history and storytelling. Basically these teaching methods were grouped under students centered approaches and needs full participation and motivations of learners. Some of the methods need students' critical thinking and continuous engagement with external communities.

In addition to the practices of student centered approach majority of teachers responded that they use students' mother tongue for the purpose of clarifications. On the other hand some teachers believed that using mother tongue have an impact on the target language. It make students dependent of translation and slowdown their language development. In Chaudron (1988) explains about the uniqueness of the language classroom "language is not only the subject of teaching; it is the means for organizing and controlling the classroom as well. The teacher's language is very important in language teaching as it provides learners with most of the input they receive." So, using student's mother tongue would be a one method to increase students' motivation, but needs attention not to dominate the status of the target language.

As we have explained before most teachers believe that several problems are facing the language learning process. The following suggestions are forward by teachers to solve this problems. 
- Showing positive expectation and attitude to students

- Teachers continuous follow up of students' progress and their participation in group activities.

- Develop students awareness on language equality and use

- Using communicative language approach

- Increase availabilities of teaching aids and reference materials

- Giving task that needs students interaction with the community and report to the class

- Increase students participation in extra-curricular activities (Establishing literature and reading clubs, weekly question and answer program)

- Using different classroom management system (controlling those students who laugh with students who committed mistakes)

- Helping students to correct their mistake by themselves than insulting or discriminating

- Developing training and CPD programs

\section{Parents Support}

Based on the response of parents, $43.75 \%$ (7), $31.25 \%(5)$ and 25\%(4) used Afan Oromo, Amharic and both languages respectively at home to communicate with their children. This indicates majority of parents are monolingual but they have positive feeling for their children to learn several languages. Even if majority of parents have positive attitude to multilingualism, they need their children to be fluent in English than in Afan Oromo or Amharic. It is because of English is medium of instruction in high school to university and help their children to perform well in mathematics and science; and English is an international language, so it encourages children to get scholarships in other countries and opportunities to travel to countries. On the other hand some of respondents have strong feeling of no need of learning Afan Oromo and Amharic in the school. The main reason was that their children could acquire all adequate standard of fluency in the languages at home. So they advise their children to spend more time on science subjects.

However, educated parents preferred their children to learn Afan Oromo, Amharic and English languages at school equally. The reasons why they preferred their children to learn their mother tongue were: they considered that since the language expresses their identity and their culture, norms and customs, their children will know more about their identities by learning the language. Besides Amharic speaking parents thought that the use of Amharic in the selected town was influenced by the dominant language (Afan Oromo) therefore, the children should have high proficiency of Amharic by learning the language in a formal setting to preserve their identity. They also supposed that being fluent in Afan Oromo helps their children to get employment at the regional, zonal and woreda levels of administration where Afan Oromo is the working language.

Afan Oromo native speakers also need their children to learn Amharic at a formal setting. They believed that as Amharic is used in selected town, it helps their children to communicate with people who were nonnative speakers of Afan Oromo. Also they thought that Amharic is the official language of Ethiopia, it helps children to participate in national issues, to be employed outside Afan Oromo-speaking areas, and to listen mass media transmitted programs in Amharic.

The main reasons why educated parents wanted their children to learn English were (as indicated above) that since English is used as a MOI beginning from grade 9 in Oromia regional state, Ethiopia, they considered that being fluent in English helps children to understand subjects easily and to enter higher educational institutions, and get scholarships.

From the aforementioned points we can see that getting and maximizing job opportunities encourages respondents to ensure their children are fluent in the three languages. Therefore, we can see that the respondents of this study were positive about multilingualism and multilingual education which is to be expected since the selected towns are a multilingual area.

So, parents' attitudes toward a second or foreign language and its people have a great effect on their children's success in learning this language. This attitude can be either negative or positive. It is proven that children have a better language achievement if their parents have positive attitude towards this language even if these parents do not speak the language. And the opposite is correct if the parents have a negative attitude towards a language.

Majority of parent respondents assumed that they don't have any role in students' language development except buying English dictionary. Some of respondents' far beyond supporting in educational resources like ensuring that children complete their homework and helping with it when they can; attending the parents meetings at school; and keeping track of their children's academic progress. This resulted from their educational status. As indicated in the background information of respondents, more than half of student families educational status were elementary and below.

International studies indicate that parental education influences expectations, in that having higher parental education is significantly related to having higher expectations of children's achievement. However, it is also likely that parents with higher education have higher attaining children for whom they have higher expectations (Davis 
and Schnabel; 2001).

Most of parents reported that teaching students at early age have positive effect on students' language development. But they worried on statuesque of their language; if students know more languages they may lose their mother tongue. On the other hand, parents believe that their children were poor in English, whereas they were good in their mother tongue (either Afan Oromo or Amharic). Their evaluation was based on children speaking skill not on knowledge of the language and other skills (writing and reading).

According to parent respondents involving in children education means getting training in a subject and offering to students. They responds that teaching students is the only responsibility of teachers and school administrations. Because of this majority of parents except those who were teachers - were went to school either their child show improper behavior or end of academic year to participate in parents' day. Even some of parents doesn't know their child teacher let alone to communicate with them.

But scholars suggested that to make difference in students' education school and parents' relationship is crucial. According to Drake $(2000 ; 34)$ "The challenges that students in schools face cannot be solved by educators alone; nor can these problems be solved by parents or families alone. Students in schools across this nation are confronted by critical social, emotional, and environmental problems. More collaboration between the school and home will need to be focused on dealing with these problems."

Therefore, parents support in improving students' language skill was not satisfactory. They need support from teachers and school administration.

Challenges in students' Second and foreign language learning Table 13:- Challenges in L2 and Foreign language Teaching-Learning

\begin{tabular}{|l|l|l|l|}
\hline & Mean & Standard deviations & Rank \\
\hline Shortage of text books & 8.1197 & 3.12401 & 1 \\
\hline Lack of students motivation & 7.979 & 2.51304 & 2 \\
\hline Fear of mistake & 7.5860 & 2.73162 & 3 \\
\hline Parents influence not speak the language & 6.6057 & 3.08082 & 4 \\
\hline Fear of friends & 6.3227 & 2.55448 & 5 \\
\hline The nature of language is complex & 6.2028 & 2.91758 & 6 \\
\hline Shortage of class time & 5.9113 & 2.80492 & 7 \\
\hline Absence of native speaker & 5.2117 & 3.06087 & 8 \\
\hline Problems in teachers teaching method & 5.0686 & 2.86388 & 9 \\
\hline Simply I hate the language & 4.2831 & 3.19432 & 10 \\
\hline Lack of community support & 4.2647 & 2.96905 & 11 \\
\hline
\end{tabular}

The questionnaire survey of students and teachers focus group discussion confirm that the following issues were considered as challenges in the second and foreign language teaching - learning process.

i. Shortage of Text books: - Based on the data gathered from respondents, shortage of language text book in the schools was one of the major challenges in second and foreign language learning $(\mathrm{M}=8.11)$. In the focus group discussion conducted with teachers also identified that the ratio between text book and students was high i.e. one text book for 10 students.

In most schools there wasn't enough text books for all teachers and students in the various grades. Teachers use different methods like sharing from other school, use their own personal funds to make photocopies of sections of the books that they needed for their lessons. An example of this is given in teacher responses:

“.... the teacher and the students don't have enough text book; so what we do is we have to photocopy and sometimes we write things up on the blackboard which is time consuming and affect students continuous practice from the book. The paper also a problem in our schoole".

While another teacher commented that there was a shortage of students text books due to the increasing number of students in her class, some teachers claimed that there was hardly any text books for students in their schools.

ii. Lack of Motivations: - The respondents put lack of motivation as the second factor that affect students' language skill to become poor $(\mathrm{M}=7.98)$. The data obtained from teachers in questionnaire survey as well as focus group discussion indicates that the students lack motivation in doing class and homework, in participating in the class room even some of them were not interested in attending language class especially Amharic or Afan Oromo subjects. That is the reason why most of students suggest raising students motivation was the core activities to be performed by teachers through different techniques. Lack of motivation was not only students problem; it also concerns teachers interest to teach the subject well. Some of student respondents raise question on teachers' interest, preparation and readiness to help their students.

In second language learning theories, it is suggested that motivation can be defined in relation to two factors: the needs of the learners; and their attitudes towards the second language and the second language community. Learners are motivated if they need to learn the language in order to achieve a goal or if they want to communicate with speakers of the target language and learn about the country where the language is spoken (Nakanishi T, 2002). 
Majority of teachers reported that students are considered motivated if they are actively involved in a task and the main aim of language teachers is to encourage as many pupils as possible to be involved in classroom activities hoping that this will aid learning. According to Wilhelm (1999) Attitudes are related strongly to motivation, it is evident that people with a negative attitude towards a language could not be motivated learners, and there is evidence to support the correlation between the positive attitude about a language and high achievement.

iii. Fear of Mistake: - Of course for majority of students, Amharic/ Afan Oromo is their second language and English is a foreign language. When speak or write in the language they committed error in pronunciations, grammar, concepts. Due to this the other students (who advance the language) may laugh with them. This led them to be silent in the class. Gradually they may lost interest in learning the language. One teacher in the discussion respond that

"Students are so much afraid of failure, therefore they are unwilling to participate in the lesson. When it comes to motivation, in my opinion it plays the most important role in the learning process. Even if you have all the other features you cannot learn a language unless you don't have enough motivation, selfconfidence etc. Your learning process will definitely result in failure if you don't trust yourself and a forcing effect no matter how hard you try"

iv. Negative influence of Parents: - Parents influence not to speak the language was the fourth challenge as ranked by the students. According to Shibata $(2000 ; 340)$ "A child does not become bilingual spontaneously. Children need parents who want them to become bilingual and who give their effort and patience toward that goal". Some teachers reported that some parents have a negative feeling in their children learning. They considered that studying a second language was just waste of time and no value for students' future academic life - it was not necessary for University/Preparatory Entrance Examination.

v. The Complex Nature of Language: - student respondents replied that the language itself is complex to learn. This was depend on the age of students start to learn the language. Almost all of students start to learn Amharic and Afan Oromo from grade five as a second language. Writing system of Amharic and Afan Oromo create some confusion for L2 learners. The Ethiopic writing system is new and complex (there are different symbols but the

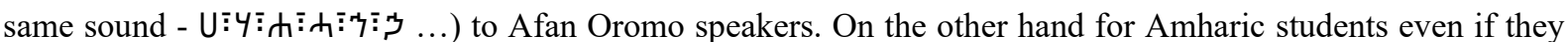
are familiar with the Latin symbols their pronunciation in English and Afan Oromo is different. Due to this both students convinced them that they were not capable in the language.

In the discussion made with teachers regarding on starting age of students identified that within one year (in grade 5) the students were expected to identify the alphabet (Symbols) and to construct complex language structures (like writing Essay). Then the students become busy and move quickly from activity to activities without complete understanding of the concept. After four years (in grade 9) the students attend the same class with native speakers (who learned the subject starting from grade 1). So, the second language learning program designed by the Regional state or MOE have contribution for poor performance of students' language competence and less motivation to learn the language.

Carroll $(1975 ; 275-6)$ "for the average student in an academic program under the typical conditions of instruction it was estimated that between six and seven years of instruction would be required to achieve commonly accepted levels of competence in all four fields of listening, speaking, reading and writing in second/foreign language. This estimated time could be reduced by one year for highly motivated students and by one further year for high-ability students." But in our context it is difficult to attain the commonly accepted levels of competence in second language learning with one or two period of instruction given a week.

vi. Problems in the allocation of class time: - in connection with the aforementioned problem, shortage of class time was another challenge in L2 learning. Afan Oromo and Amharic subject was taught for non-native speakers only one/two periods per week - it vary from school to school (one period is 40 minutes). Regarding class time all teachers except English language teachers' (English allocated 4 periods a week for one section) claim that the time given for the subject and the content to be covered was not proportional. The text book is wide; to cover all contents the teachers perform activities themselves without the participations of students.

Those teachers who spoke on this topic indicated that most teachers were hard working, creative and very concerned about the performance and progress of their students' proficiency levels in the language, but due to shortage of time the performance of students were not at the required level. An example of this is shown in one teacher's responses:

"... most students cannot even read or write and they find it hard. So we have to go back again to revise the basic points when we get time or we engage them with students who are well advanced so that they help them out in the classroom. To do this there is shortage of time".

vii. Problems in teaching method: - most students considered it is not a serious problem in their language learning but some students raise constructive comments. These students claim that the teachers doesn't have positive feeling for L2 learners, insulting students when they give wrong answer, simply write on board than practicing, waste the class time, dependent only on the text book.

Moreover, majority students reported that absence of native speaker, stereotype on the language and lack of 
community support have small influence on their language development. But the discussion conducted with teachers revealed that communities influence on students' second language learning was high. They related with political ideology and religious influence. Most communities see Amharic as the language of Christians and the past government. They believe it is the language of conquest and it can decrease the status of Afan Oromo. Not only has the community, the administrative bodies also have such attitude. On the other hand Amharic speakers

Teacher respondents also listed some challenges in addition to the above mentioned. First and most quality of teachers are the serious problems in the selected zone. For that anyone who can speak the language can assigned to teach the subject without qualification and preparations. In the discussion one teachers said that "I was graduated in Geography but I can speak Amharic better than the other teachers. So I assigned to teach Amharic for grade seven and eight students. It is common in rural schools due to shortage of teachers". This resulted from absence of educational institution which offers Amharic at a diploma level in the region in any program. On the other hand the teachers work load was high and take responsibility to teach several subjects in a large class size. This creates a great burden on teachers to follow up their students and to use student centered approach.

\section{CONCLUSION AND RECOMMENDATIONS}

Conclusion

This study was designed to assess students and teachers attitude towards multilingualism in selected primary schools of Bale and West Arsi zone. To answer the research questions mixed research approach was employed and the required data collected through questionnaire, interview and focus group discussion. Thus, 45 teachers and 391 students filled questionnaires; 16 parents were interviewed and 8 focus group discussion was conducted with teachers. The data collected from teachers and students through the questionnaire were classified and tabulated; mean, median and standard deviation were computed and interpreted. Besides, independent sample t-test on gender, mother tongue and medium of instructions were calculated. Data obtained from interview were analyzed thematically and used to cross check teachers and students response.

On the basis of the data collected from respondents the study has come up with the following findings;

The results of the student survey shows that these students have positive attitude towards the linguistic diversity surrounding that they live in - this means the students have positive attitude to learn Afan Oromo, Amharic and English Languages. But their participation in the class or communicative abilities of the languages wasn't satisfactory. The main reason for poor communicative skill and low participation in the second and foreign language class room was lack of motivation both from students and teachers, shortage of text books, fear of mistake, parents' negative attitude to the language, fear of friends, shortage of class time, shortage of well trained teachers in the language, teachers over load and etc...

The independent t-test revealed that students' gender doesn't show any influence on their attitude to Amharic/Afan Oromo and English language as well as multilingualism. Whereas, students mother tongue and medium of instruction have significant effect on their attitude to learn their second and foreign languages but not on their feeling to learn diverse languages. Based on this Amharic speaker and MOI students have more positive attitude than Afan Oromo speaker and MOI students towards learning Afan Oromo/Amharic and English language .So, students' attitude to multilingualism wasn't statistically associated with mother tongue and medium of instruction.

Moreover, result of teachers questionnaire survey shows that teachers have positive attitude towards multilingualism and there was no observed statistical difference on their gender and mother tongue. Teachers included in the FGD as well as survey indicate that they are working hard to attain the expected objectives through employing student centered teaching approach. But they believed that their students have negative attitude to the language. Here, there was a conflicted ideas among students and teachers on attitude to language class room. According to researchers' belief teachers take students' lack of participation in the class as a negative attitude to the language. But low participation always doesn't show negative attitude. Because of the aforementioned problems the students may not be motivated or the way teachers teach may not be comfortable to them even if they use participatory approach. Hence, it is better to understand that students attitude to second and foreign language was positive but their participation in and out of class was low.

The behavior and skills of the instructor. Behavior that have been shown by instructor, such as supportive, understanding, approachable, friendliness through positive nonverbal behavior, giving smiles and nodded for admitting the answers that are given by students $\bar{\AA}$ Environmental factor such as the size of classroom the, perception of classmates the traits or feeling shown by peers or classmates skills of the instructor, personality of the students

Furthermore parents support on students language learning was not at the expected level. Even if majority of parents believed that learning more language have a positive effect on students' future life they were not participated in the teaching and learning process. This resulted from knowledge gap from the parents themselves and the experience of school administrative bodies and teachers in involving parents was low. In addition the instrumental approach of language is more than instrumental approach. All of research participants reported that 
the main reason to know the language was to secure better job opportunities.

In conclusion, schools play a significant role in the promotion or demotion of languages, cultures and identities Whether the students' positive attitudes stem from the general school climate, the teachers' attitudes and methods or their family and friends is inconclusive and may well be a combination of the above, overall it must be said that students within Bale and west Arsi zone primary school are positively inclined towards language diversity. This quality is necessary in order to survive in a global perspective. The world is evolving and individuals who have multilingual and multicultural knowledge and awareness as a resource will have a clear advantage in life and choices become limitless as the world becomes their stage. The fostering of students with clear and confident identities that are cross-cultural and international will be what the market calls for in the near future. These students will influence the world and our aspiration is that they truly become international citizens of the world.

\section{Recommendations}

Based on the finding and conclusions of the study the following recommendations were forwarded;

1. All of language classroom are not liked by students. It depend on conditions like physical environment, the age and the motivation of the students, the amount of time available for learning, principles which guide teachers in their language teaching methods and techniques and many other variables. Second/Foreign language teachers are the responsible one in motivating the learners to reach the objectives take into consideration the individual differences, learner characteristics and plan the activities in this regard.

2. It is clear from the data that students need help in the three language both in and out of the classroom to develop their motivation and communicative skills. So, teachers and parents are the key players in helping their students/children to achieve the ultimate goal of securing job opportunities and, therefore, need to play their part if they wish to see their students/children become successful in life. Parents in particular could provide an avenue at home where their children are able to practice the languages, a wish that was expressed by a student in this study who wishes to see their parents speak Afan Oromo/Amharic and English to them at home to develop their language skill. Besides parents should accept and teach their children on language equality.

3. Moreover, the staff lack in experience and knowledge of working to support parents in engaging with their children's learning. The concerned bodies, like school administrative bodies, higher educational institutions (Madda Walabu University and Robe teachers college) have a responsibility to feel the gap through trainings. Also, college of social science and humanities should plan and implement comprehensive awareness creation program regarding on language use and equality for all stake holders (Teachers, students, parents/communities and educational administrative bodies); developing teachers capacity on theories and practices of communicative language approach and language class room management.

4. Our second language program should have to be assessed whether it achieved the required objectives or not. Because there are several problems revolved around it. The time allocated for the subject, shortage of text book, the organization of text book, shortage of teachers, the starting age of students, continuity (both native and second language learners attend the same program and sit for common national examination). The weight of the language in the national examination. For example, the score of Afan Oromo was took as entrance to Grade 11(both for native and second language learners) but Amharic was taken as elective (based on the interest of student).

5. The Ministry of Education and Oromia regional state have the responsibility to support schools through fulfilling the required resources. The primary resource is quality and availability of teachers. The subject (especially Amharic) is taught by unqualified teachers. This leads students to develop a passive attitude to the subject matter. This came as a result of absence of educational institutions which offer Amharic subjects at diploma level. All of teacher training colleges of Oromia are suspend their Amharic language program but the subject is given starting from grade five for second language learners and for minority nations starting grade 1 to preparatory level with difficulties. So, teaching these students by unqualified teachers violate their human right. Both international laws and our constitutions affirms that children have the right to get education in their mother tongue with trained teachers.

6. The attitudes that most seem to have are those of open-mindedness, tolerance, acceptance, respect, curiosity and appreciation. These attitudes influence the way in which learning languages is approached and this in turn influences the general classroom atmosphere and the method in which learning is conducted.

\section{REFERENCES}

Alemgena Belete (2008) Attitudes and motivation of students learning Afan Oromo as a second language: The 
Case of Adama senior secondary school. MA thesis. Addis Ababa University.

Baker C., (1992). Attitudes and Language, Clevedon: Multilingual Matters Ltd.

Baker, C. (1996). Foundations of Bilingual Education and Bilingualism (2 ${ }^{\text {nd }}$ Ed.). Clevedon, Avon: Multilingual Matters.

Baker, C. (2001). Foundations of Bilingual Education and Bilingualism ( $3^{\text {rd }}$ Ed.). Clevedon: Multilingual Matters.

Baker, C. (2006). Foundations of Bilingual Education and Bilingualism (4 ${ }^{\text {th }}$ Edition). Clevedon: Multilingual Matters.

Ball, J. (2010). Enhancing learning of children from diverse language backgrounds: Mother tongue-based bilingual or multilingual education in the early years. A paper prepared for UNESCO 2010. Retrieved $15^{\text {th }}$ March 2010 from: http://www.ecdip.org/docs/pdf/UNESCO\%20Summary\%202010.pdf

Chaudron (1988) Second Language Classrooms: Research on Teaching and Learning. Cambridge: Cambridge University Press.

Clyne, M. (1997). Multilingualism. In: Coulmas, F. (ed.). The Handbook of Sociolinguistics (Oxford/UK and Malden/USA: Blackwell), 301- 314.

Cohen, G, P.E (2000). Identity and Opportunity: The Implication of Using Local Languages in the Primary Education System of the Southern Nations Nationality and Peoples Region (SNNPR), Ethiopia. PhD Thesis, School of African and oriental studies- London University.

Cohen, G, (2006) The Development of regional \& local languages in Ethiopia's federal

system. Ethnic Federalism: The Ethiopian Experience in Comparative Perspective, ed. David Turton, 165-180. Oxford: James Currey Ltd.

Cook, V. (1996) Second Language Learning and Language Teaching, London: Arnold

Crystal, D. (2011). From the World to the Word-and Back Again. Plenary lecture given to the CILT Primary Languages Show, 'From the Word to the World', Liverpool, 4 March.

Cummins, (1999). Research, ethics, and public discourse: The debate on bilingual education. Presentation at the National Conference of the American Association of Higher Education, March 22, 1999. Retrieved From $\mathrm{http}$ ://ourworld.compuserve.com/homepages/JWCRAWFORD/cummins2.htm.

Cummins, J. (2000). Language, power and pedagogy. Bilingual children in the crossfire. Clevedon: Multilingual Matters.

Danial Alemu \& Abebayehu Tekleselassie. (2011). Comparative Analysis of Instructional Language Issues in Ethiopia and United States. Creative Education 2,4: 402-407.

Davis-Kean and Schnabel, K. U. (2001) 'The impact of socio-economic characteristics on child outcomes: The mediating role of parents' beliefs and behaviors'. Child Development, under review, in Feinstein, L. Duckworth, K, and Sabates, R (2004) A Model of the Intergenerational Transmission of Educational Success. Wider Benefits of Learning Research Report 10. London: Institute of Education.

Dörnyei, Z. (2007). Research Methods in Applied Linguistics: Quantitative, Qualitative and Mixed Methods. England: Oxford University Press.

Edward, J. (1994). Multilingualism. London: Penguin Books Ltd.

Fasold, R. 1984. The Sociolinguistic of Society. England: Basil Blackwell Ltd.

Flores, B. (2001). Bilingual education teachers; beliefs and their relation to self-reported practices. Bilingual Research Journal, 25, 251-275.

Ganschow, L., R.L. Sparks, and J. Javorsky. (1998). "Foreign Language Learning Difficulties: An Historical Perspective." Journal of Learning Disabilities 31(3): 248-58.

García, O. (1997). Bilingual Education. In F. Coulmas (Ed.), The Handbook of Sociolinguistics (pp. 405-420). Oxford: Basil Blackwell.

Gardner, R. C. (2001). Language learning motivation: The student, the teacher, and the researcher. Texas Papers in Foreign Language Education, 6, 1-18.

Gashaw Arutie (2012) Attitudes to Gamogna, Amharic and English Languages in Primary Schools: In the Case Of Arba Minch Town. MA thesis. Addis Ababa University.

Getachew, A., Derib, A. (2006) Language Policy in Ethiopia: History and Current Trends. In Ethiopian Journal of Education \& Science, vol. 2, no. 1, pp. 37-62.

Gonzáles, R. D., with Melis, I. (2000). Language Ideologies: Critical Perspectives on the Official English Movement, Vol. 1: Education and the Social Implications of Official Language. Urbana, IL and Mahwah, NJ: National Council of Teachers of English: Lawrence Erlbaum.

Guerini, F. (2007) Multilingualism and language attitudes in Ghana: a preliminary survey. Università degli Studi di Bergamo.

Heugh,K et al.(2007). Final Report on the Medium of Instruction in Primary Schools in Ethiopia. From, http://www.hsrc.ac.za/research/output/outputDocuments/4379\.Pdf.

Hoff, E. (2001). Language development (2nd ed.). Belmont, California: Wadsworth/ Thomson Learning.

Hohenthal A.(2003) English in India: Loyalty and attitudes, Language in India, 3, 1107, 
http://www.languageinindia.com Accessed on 2 September 2006.

Holmes, J. (1992). An introduction to sociolinguistics. London: Longman.

Ihemere, K.U. (2006). An Integral Approach to the Study of Language Attitudes and Change in Nigeria: The Case of Ikwerre of Port Harcourt city. Selected Proceedings of the 36th Annual Conference on African Linguistics.

Jessner, U. (2008). Teaching third languages: Facts, trends and challenges. Language Teaching 41(1):15-56.

Krashen, S. (1996). Under Attack: The case against bilingual education. Cilver City, CA: Language

Krueger, R., \& Casey, M. A. (2009). Focus groups: A practical guide for applied research. Los Angeles: Sage publisher.

Lanza, Elizabeth and Hirut Woldemariam (2014) Multilingualism and Local Literacy Practices in Ethiopia: Language contact in regulated and unregulated spaces; Multilingual Margins 1(1): 74-100

Lazaraton, A.(2005) . Quantitative research methods in E. Hinkel (ed). Handbook of Research in Second Language Teaching and Learning. Mahwah, N.J.: Lawrence Erlbaum.

Lefebvre, E. (2012). Student Attitudes toward Multilingual Education: MA thesis, Graduate School of the University of Oregon.

Lewis, M. Paul (ed.). 2009. Ethnologue: Languages of the World. Sixteenth edition. Dallas, Tex.: SIL International. Online version: http://www.ethnologue.com/.

Lightbown, P. and Spada, N. (1993) How Languages are Learned, Oxford: Oxford University Press.

Luján, A. A., and Armendáriz, E. J. (2002). An administrative perspective of a two-way bilingual immersion program. Bilingual Research Journal, 26(1), 169-179.

May, S. (2008). Bilingual/immersion education: What the research tells us. In J. Cummins \& N. H. Hornberger (Eds.), Encyclopedia of Language and Education, ( $2^{\text {nd }}$ Ed.), Volume 5: Bilingual Education, (pp. 19-33). New York: Springer Science + Business Media

McKenzie, R. M. (2010). The Social Psychology of English as a Global Language: Attitudes, Awareness and Identity in the Japanese Context. United Kingdom: Routledge.

Mequanint Wana. (2009). Attitudes toward Gamognatstso as MOI in the first cycle of primary education in Gamogofa zone. MA thesis. Addis Ababa University.

Meyer, R. (2006). Amharic as lingua-franca in Ethiopia. Lissan: journal of African language and linguistics 117131.

MOE (1994) . Education and Training Policy of Ethiopia. Addis Ababa.

Nakanishi, T. (2002). 'Critical Literature Review on Motivation', Journal of Language and Linguistics, 1, (3), 278 $-287$

Pool J.(1969) National development and language diversity: La Monda Lingvo-Problemo, 1: 140-56, London Rotterdam.

Romaine, S. (1989). Bilingualism. New York, NY: Basil Blackwell Inc.

Santa Cruz, CA: Centre for Research on Education, Diversity, and Excellence. Retrieved 21 September

Schumann, J. H. (1978). The pidginization process: A model for second language acquisition. Rowley Mass: Newbury House.

Shameem, N. (2004). Language Attitudes in multilingual primary schools in Fiji. Language, Culture and Curriculum, 17(2), 154-172.

Shibata, S. (2000). Opening a Japanese Saturday school in a small town in the United States: community collaboration to teach Japanese as a heritage language. Bilingual Research Journal, 24(4), 333-342.

Shin, F. H., and Gribbons, B. (1996). Hispanic parentse perceptions and attitudes of bilingual education. Journal of Mexican American Educators, 6, 16-22.

Silin, J. G., and Schwartz, F. (2003). Staying close to the teacher. Teachers College Record, 105(8), 1586-1605.

Sirgar, F. L. (2010). The Language Attitudes of Students of English Literature and at Maranatha Christian University toward American English, British English and English's in South West Asia and their Various Contexts of Use in Indonesia. Philippine ESL Journal 4: 66 -92.

Skutnabb-Kangas, T. (1999). Linguistic diversity, human rights and the free market. In M. Kontra et al. (Eds.), Language: A right and a resource - Approaching Linguistic Human Rights (pp.187-222). Budapest: Central European University Press.

Skutnabb-Kangas, T. (2000). Linguistics Genocide in Education - or Worldwide Diversity and Human Rights? New Jersey: Lawrence Erlbaum Associates.

Spolsky, B. (1989). Conditions for second language learning Introduction to general theory. Oxford: Oxford University Press.

Tahar, L. (2005). Attitudes towards foreign language (Arabic/ Hebrew) and readiness to communicate in this language among Jewish and Arab students in Israel, attending regular schools and the bilingual school in Neve Shalom. Master Thesis, Tel Aviv: University of Tel Aviv.

Thomas, W., and Collier, V. (2002). A national study of school effectiveness for language minority students' long term academic achievement. 
Tsehaye Tefera (1977). A Sociolinguistic survey of language use and attitudes towards language in Ethiopia: Implications for language policy in education. $\mathrm{PhD}$ dissertation. Georgetown University: University microfilms international.

UNESCO (1953). The use of vernacular languages in education. Monographs on Foundations of Education, No. 8. Paris: UNESCO.

Uprichard, E. (2008). Children as 'being and becoming's': Children, childhood and temporality. Children \& Society, 22, 303-313. doi: 10.1111/j.1099-0860.2007.00110.

Varghese, M. M. (2008). Using cultural models to unravel how bilingual teachers enact language policies. Language and Education, 22, 289-306.

Weinburg, M. H. (1998). Gender, ethnicity and grade level as predictors of middle school students' attitudes $\begin{array}{llllll}\text { towards } & \text { science. } & \text { Retrieved } & \text { May } & \text { 12, }\end{array}$ http://www.Ed.Psu.Edu/Ci/Journals/1998aets/S5_1_Weinburg.Rtf

Wenden, A. L. (2002) 'Learner Development in Language Learning', Applied Linguistics 23/1:32-55

Wolff, E. (2000) language and Society: In; Heine, B. and Derek Nurse (eds.), African Languages: An Introduction, 298-347.

Wright, M. (1999). Influences on learner attitudes towards foreign language and culture. Educational Research, 41(2), 197-208.

Zeevi, A. (1995). Comparison of motivation and attitudes of students toward school subjects: English, Arabic and French. Master Thesis, Tel Aviv: University of Tel Aviv.

Zelalem Leyew .(2012). The Ethiopian Language Policy: A Historical and Typological overview. Ethiopian Journal of Language and Literature Volume 12 No. 2: P1-59.

Zelazo, J. (1995). Parent involvement in a two-way bilingual school. Paper presented at the Annual Meeting of American Educational Research Association (San Francisco, California. April 18-22, 1995).

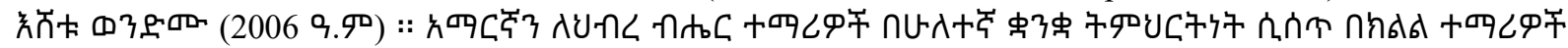

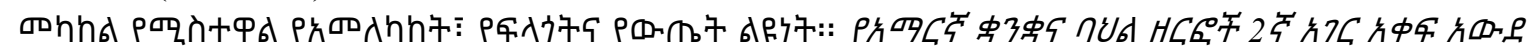

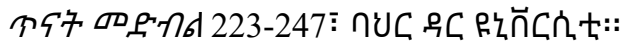

http://homepage.ntlworld.com/vivian.c/SLA/SLAQuotes.htm 